\title{
Érica Bezerra Nobre
}

Elaboração e validação de questionário para descrever o estilo de vida de mães de pré-escolares

Dissertação apresentada à Faculdade de Medicina da Universidade de São Paulo para obtenção do título de Mestre em Ciências

Programa de Pediatria

Orientador: Prof. Dr. Alexandre Archanjo Ferraro

São Paulo

2012 


\section{Érica Bezerra Nobre}

Elaboração e validação de questionário para descrever o estilo de vida de mães de pré-escolares

Dissertação apresentada à Faculdade de Medicina da Universidade de São Paulo para obtenção do título de Mestre em Ciências

Programa de Pediatria

Orientador: Prof. Dr. Alexandre Archanjo Ferraro

São Paulo

2012 


\section{Dados Internacionais de Catalogação na Publicação (CIP)}

Preparada pela Biblioteca da

Faculdade de Medicina da Universidade de São Paulo

Creprodução autorizada pelo autor

Nobre, Érica Bezerra

Elaboração e validação de questionário para descrever o estilo de vida de mães de pré-escolares / Érica Bezerra Nobre. -- São Paulo, 2012.

Dissertação(mestrado)--Faculdade de Medicina da Universidade de São Paulo. Programa de Pediatria.

Orientador: Alexandre Archanjo Ferraro.

Descritores: 1.Estilo de vida 2.Pré-escolar 3.Relações mãe-filho 4.Questionários 5.Estudos de validação

USP/FM/DBD-053/12 
À minha família 


\section{AGRADECIMENTOS}

Quero agradecer a Deus por ter me concedido a oportunidade de compreender um pedacinho da realidade feita por Ele.

Ao professor Alexandre pelo convite em fazer esta pesquisa e pela paciência que teve nas orientações dadas.

Aos meus pais por serem eles os meus pais e por sempre me apoiarem.

Aos meus lindos irmãos, Ronaldo e Angela, por me ajudarem a não perder de vista o Alvo da vida.

À Marina, pela minha acolhida em sua casa e pela companhia que me fez.

Aos amigos de Comunhão e Libertação de Brasília e São Paulo por me ajudarem a subir mais um degrau na vida.

Aos colegas de grupo de estudo, Augusto, Tereza e Adriana pelas contribuições que deram a esta pesquisa.

Aos professores Dr. Celso Cláudio de Hildebrand e Grisi, Dra. Sandra Josefina Ferraz Ellero Grisi e Angélica Riello pelas contribuições que fizeram no desenvolvimento do questionário. 
À Patrícia e Sônia pela permissão de realização dos pré-testes.

Aos pesquisadores de campo Gisele, Natália, Paula e Danilo pela persistência e dedicação que tiveram na coleta de dados.

À secretária do departamento de Pediatria, Adriana Bezerra, por todo auxílio prestado durante o cumprimento desta pesquisa.

À Marisa, pelo auxílio no levantamento bibliográfico.

Ao Nivaldo, pelas cópias do material de pesquisa.

Agradeço de coração a todos aqueles que de algum modo contribuíram para o desenvolvimento deste trabalho. 


\section{Agradecimentos especiais}

Ao Ministério da Saúde, pelo financiamento desta pesquisa.

À Coordenação de Aperfeiçoamento de Pessoal de Nível Superior (CAPEs), pela bolsa de estudo institucional para mestrado. 
"Aquele que planta nada é. "Aquele que rega nada é, mas importa tão somente Deus que dá o crescimento". 1 Cor 3,7 


\section{NORMALIZAÇÃO ADOTADA}

Esta dissertação está de acordo com as seguintes normas, em vigor no momento desta publicação:

Referências: Adaptado de International Committee of Medical Journals Editors (Vancouver)

Universidade de São Paulo. Faculdade de Medicina. Divisão de Biblioteca e Documentação. Guia de apresentação de dissertações, teses e monografias. Elaborado por Anneliese Carneiro da Cunha, Maria Julia de A. L. Freddi, Maria F. Crestana, Marinalva de Souza Aragão, Suely Campos Cardoso, Valéria Vilhena. 3a ed. São Paulo: Divisão de Biblioteca e Documentação; 2012.

Abreviatura dos títulos dos periódicos de acordo com List of Journals Indexed in Index Medicus. 


\section{SUMÁRIO}

Lista de abreviaturas

Lista de siglas

Lista de tabelas

Resumo

Summary

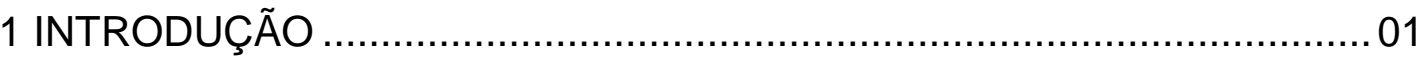

1.1 Estilo de Vida Epidemiológico ..................................................... 04

1.2 Estilo de Vida Sociológico ....................................................... 05

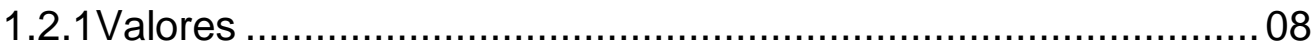

1.3 Elaboração e Validação de questionário .......................................11

1.3.1Definição de construto ................................................... 12

1.3.2 Formulação dos itens .................................................. 12

1.3.3 Adequação semântica dos itens ........................................ 13

1.3.4 Escalonamento de respostas ......................................... 14

1.3.5 Realização do pré-teste.................................................... 14

1.3.6 Consolidação do instrumento ............................................. 15

1.3.6.1 Dimensionalidade .................................................... 15

1.3.6.2 Confiabilidade ...................................................... 15

1.3.6.3 Validade ............................................................. 17

1.3.6.3.1 Análise fatorial ................................................. 18

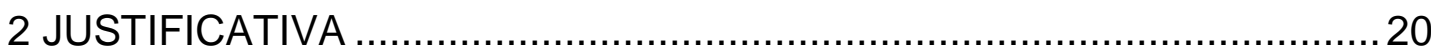

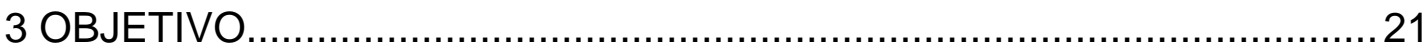

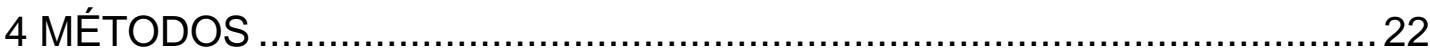


4.1 Desenho do estudo

4.2 Variáveis coletadas e instrumento ............................................. 22

4.3 Construção do instrumento ...............................................23

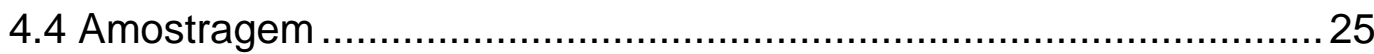

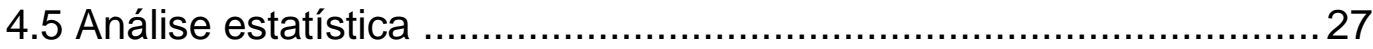

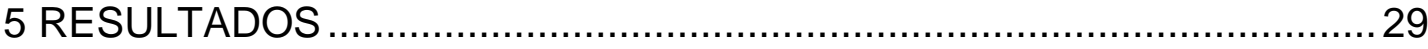

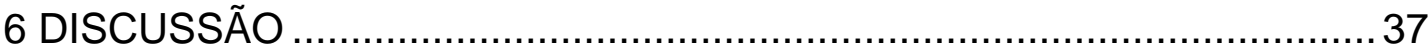

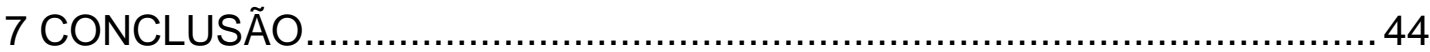

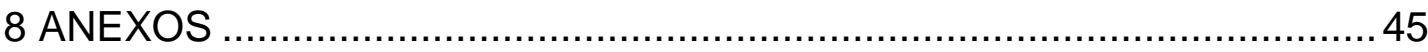

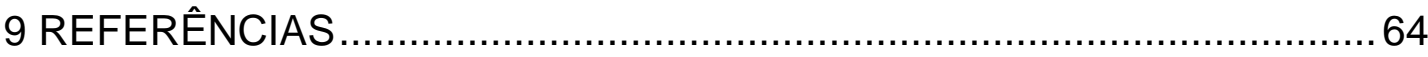




\section{LISTA DE ABREVIATURAS}

$\begin{array}{ll}\text { AIO } & \text { Atividades, Interesses, Opiniões } \\ \text { AIOV } & \text { Atividades, Interesses, Opiniões, Valores } \\ \text { EdV } & \text { Estilo de Vida } \\ \text { EVR } & \text { Escala de Valores de Rokeach } \\ \text { EVS } & \text { Escala de Valores de Schwartz } \\ \text { LdV } & \text { Lista de Valores } \\ \text { LDL-C } & \text { Low density lipoprotein cholesterol } \\ \text { HDL-C } & \text { High density lipoprotein cholesterol }\end{array}$




\section{LISTA DE SIGLAS}

ABEP

AMA

OMS

$\mathrm{SP}$

USP

WHO
Associação Brasileira de Estudos Populacionais

American Marketing Association

Organização Mundial da Saúde

São Paulo

Universidade de São Paulo

World Health Organization 


\section{LISTA DE TABELAS}

Tabela 1 - Número e proporção de tipos e região das escolas de pré-escolares, Região Oeste, São Paulo, SP - 2011 29

Tabela 2 - Características da amostra segundo número, proporção e intervalo de confiança da classificação econômica, grau de instrução e estado civil de mães de pré-escolares, Região Sudoeste, São Paulo, SP - 2011 30

Tabela 3 - Proporção de famílias pertencentes às classes econômicas A, B, C, D e E no município de São Paulo em 2007 e em cinco subsdistritos da Região Sudoeste do mesmo município em 2010/2011, Região Sudoeste, São Paulo, SP - 201130

Tabela 4 - Coeficiente de correlação pairwise dos itens do questionário no estudo piloto e na pesquisa final, Região Sudoeste, São Paulo, $\mathrm{SP}-2011$

Tabela 5 - Auto valor, proporção e \% acumulado dos fatores do questionário de Estilo de Vida, Região Sudoeste, São Paulo, SP - 2011 32

Tabela 6 - Valores de carga dos fatores remanescentes do questionário AIOV de estilo de vida, Região Sudoeste, São Paulo, SP - 2011 


\section{RESUMO}

Nobre EB. Elaboração e validação de um questionário para descrever o estilo de vida de mães de pré-escolares [dissertação]. São Paulo: Faculdade de Medicina, Universidade de São Paulo; 2012.

INTRODUÇÃO: A saúde da criança é em parte determinada pelo Estilo de Vida da mãe. É preciso saber em quais dimensões ele afeta a saúde do pré-escolar, uma vez que este está sujeito às influências ambientais e de terceiros. Não há instrumento de medida a nível nacional que descreva o estilo de vida materno segundo suas atividades, interesses, opiniões e valores e que possa ser utilizado em associações com aspectos nutricionais da criança. OBJETIVO: Elaborar e validar um questionário capaz de descrever o estilo de vida de mães de pré-escolares. MÉTODOS: Entre janeiro de 2010 a março de 2011 realizou-se um estudo transversal com mães de pré-escolares moradoras em cinco subdistritos na Região Sudoeste do município de São Paulo. Selecionou-se uma amostra probabilística aleatória estratificada proporcional, com dois estratos, sendo primeiro sorteadas as escolas e depois as crianças. Foram coletadas informações sobre a idade, classificação econômica, grau de instrução e estado civil das mães. Três instrumentos encontrados na literatura foram utilizados para compor o questionário de estilo de vida. Eles foram submetidos a um primeiro pré-teste o qual demonstrou a necessidade de adaptação cultural e validade de conteúdo dos itens. Após eliminação de dois deles e alteração dos itens remanescentes, o questionário com cinco novas opções de resposta foi aplicado a dez mães, que não se manifestaram quanto à clareza das questões e opções de resposta. O questionário foi submetido a um estudo piloto em que foi notada a necessidade de adaptação semântica dos itens. Após alteração, foi formada a versão final do questionário a qual foi submetida a um terceiro pré-teste com seis mães. Nesse, nenhuma se manifestou quanto aos aspectos confusos ou dificuldades em dar reposta. $O$ instrumento final continha cinquenta e três itens com cinco opções de resposta cada um. Verificou-se os valores do alfa de Cronbach e dos coeficientes de correlação pairwise e o questionário foi submetido à análise fatorial. RESULTADOS: Cento e cinquenta e três mães participaram da primeira entrevista e cento e duas do reteste. As mães pertenciam a todas as classes sociais, níveis de escolaridade e estado civil, sendo que as mais freqüentes foram aquelas de classe $\mathrm{C}$, com ensino médio completo $\mathrm{e}$ casadas. O valor do alfa de Cronbach no estudo piloto foi de 0,81 e na versão final do instrumento foi de 0,83 . Os coeficientes de correlação pairwise no estudo piloto foram menores que 0,5 e na última aplicação do instrumento foram maiores que 0,5. A análise fatorial permitiu identificar sete fatores de Estilos de Vida que explicaram $71,66 \%$ da variância de intercorrelações. Foram eliminadas quinze variáveis do questionário. Os fatores foram nomeados com base no item de maior valor de carga e pelo conjunto dos itens. CONCLUSÕES: o questionário descreveu sete dimensões de estilos de vida, possui validade de conteúdo e boa confiabilidade e poderá ser utilizado em associações com aspectos nutricionais do pré-escolar.

Descritores: Estilo de vida; Pré-escolar; Relações Mãe-Filho; Questionários; Estudos de Validação. 


\section{SUMMARY}

Nobre EB. Construction and validation of a questionnaire to describe the life style of preschoolers' mothers [dissertation]. São Paulo: "Faculdade de Medicina, Universidade de São Paulo"; 2012.

BACKGROUNG: Child's health is in part determined by the mother's Life Style (LS). It is important to know in which ways it affects preschooler's health, since this age is specially influenced by environment and close people. There is no tool that measures maternal LS according to the maternal activities, interests, opinions and values and that may be used in association studies of child nutrition. AIM: to elaborate and validate a questionnaire which is able to describe the LS of preschoolers' mothers. METHOD: Between January 2010 and March 2011 a cross-sectional study with preschoolers' mothers took place in five districts of the South-west region of the city of São Paulo, Brazil. A random probabilistic stratified sample was selected, with two strata (school and child). Data on maternal age, socioeconomic status schooling, marriage status was collected. It was found in the literature three tools which helped in the construction of a LS questionnaire. This one was firstly submitted to a pre-test, suggesting the need of a cultural adaptation and content validation. After putting away two of these tools and modification of remaining items, a questionnaire with five-answering options was applied to ten mothers, who did not express any concern about the understanding. This questionnaire was used in a pilot study in which the need of a semantic adaptation was evident. After that the final version was used in 6 mothers, none of them had difficulties in comprehension. The final tool had fifty tree items, each one with five answering alternatives. The Cronbach's alpha and testretest pair-wise correlation coefficient (PWCC) were calculated. The questionnaire went through a factor analysis. RESULTS: One hundred fifty tree mothers took part in the first interview and one hundred two in a retest interview. In the pilot version the tool presented a Cronbachs alpha of 0.81 and in the final version of 0.83 . The PWCC were lower than 0.5 in the pilot tool version and above 0.5 in the final version. Factor analyses found that seven items explained $71,66 \%$ of the intercorrelation variance. Fifteen items of the questionnaire were put away. Factors were named according to their highest eigenvalues and the meaning. CONCLUSION: the questionnaire described seven LS, presented content validity and good reliability and can be used in association with preschooler nutrition.

Descriptors: Life Style; Preschool; Mother-Child Relations; Questionnaires; Validation Studies. 


\section{Introdução}

Sabe-se bem sobre a necessidade de mudança no cuidado das pessoas para um método que seja fundamentado na promoção de saúde e prevenção de doenças e não apenas no tratamento delas ${ }^{1,2,3,4}$.

Em meio à necessidade de promoção da saúde, o Governo Brasileiro, em sua Constituição de 1988, considerou a saúde como sendo um direito social de todos e dever do estado, o que não exclui o dever de todos os cidadãos em promovê-la 5 .

Promover saúde envolve um processo que permite as pessoas aumentar o controle sobre sua própria saúde e sobre seus determinantes ${ }^{6}$. Esses determinantes podem ser divididos em cinco categorias. A primeira delas envolve o ambiente socioeconômico que abrange a remuneração, trabalho, status social, educação e situação social no ambiente do trabalho. A segunda categoria refere-se ao ambiente físico em que o homem está inserido, ou seja, o ambiente que ele mesmo constrói ou o natural, entendidos como moradia e clima, respectivamente. A terceira categoria merece atenção especial por ser o objeto de estudo desta pesquisa. Ela considera as atitudes pessoais, ou seja, os padrões de comportamentos das pessoas que criam riscos ou benefícios para saúde própria ou dos outros, indiretamente entendido como estilo de vida ${ }^{3,7}$ - EdV. As capacidades individuais tais como genética, fisiologia, competência pessoal, habilidades e senso de controle caracterizam a quarta categoria. A última e quinta categoria diz respeito aos serviços de saúde, envolvendo promoção, manutenção e restauração da saúde ${ }^{7}$.

Partindo do terceiro determinante de saúde, o EdV ou o modo de viver tem grande influência no aparecimento de doenças. As telecomunicações, mídia, indústrias, comunidade etc. influenciam em grande parte os comportamentos e 
atitudes das pessoas. Entretanto, existe um grupo de indivíduos que muitas vezes não estão livres de tais influências e acabam sendo dominados pelos comportamentos dos adultos: as crianças pré-escolares. Elas constituem um grupo merecedor de atenção por serem mais vulneráveis às conseqüências de tais comportamentos $^{6,8}$, pois apresentam imaturidade fisiológica e psicológica ${ }^{9}$. Além disso, elas estão em uma fase de grande desenvolvimento das áreas social, cognitivo e emocional ${ }^{4}$.

Desde muito tempo ${ }^{9}$, tem-se falado sobre os direitos fundamentais assegurados por lei ou de outros modos para garantir o "desenvolvimento físico, mental, moral, espiritual e social das crianças" ${ }^{8}$ (p.9). Devido a esse contexto, elas têm prioridade no tratamento integral, constituindo um grande desafio em relação à promoção de sua saúde e prevenção de doenças ${ }^{9}$. Pais, professores e toda a comunidade são responsáveis pela saúde das crianças. As ações feitas em termos de promoção de saúde e prevenção de doenças para as crianças pré-escolares são fundamentais para o futuro da sociedade ${ }^{4}$.

De todas as pessoas que convivem com as crianças, os pais são os grandes responsáveis pelo crescimento e amadurecimento delas e o local onde isso acontece é na família ${ }^{9}$. Nela, a criança ganha conhecimentos básicos, forma o sistema de valores e os comportamentos de saúde e desenvolve seu EdV por meio da influência do modo de viver dos pais ${ }^{9,10}$. De forma geral, a família contribui significativamente na formação de EdV das crianças e, sobretudo, as mães, pois estão presentes na maior parte do tempo e nos cuidados dos filhos ${ }^{11,12,13}$.

Com a finalidade de compreender a influência do modo de viver dos pais, pesquisadores procuram compreender a relação existente entre hábitos alimentares dos pais e crianças $^{13,14}$. Schwandt et al. $^{14}$ (2010) conduziram um estudo com a 
finalidade de averiguar se os fatores de risco cardiovasculares são afetados pelo estilo de vida familiar. Eles constataram que o consumo energético acima do recomendado foi maior em crianças em relação aos pais. Além disso, o fato de a mãe ter alta ingestão energética aumentou em sete vezes a chance da filha também ter, enquanto que para os meninos a chance foi três vezes maior. As crianças com baixa ingestão de gordura monoinsaturada eram filhas de pais com altos níveis de triglicérides e alta razão LDL-c/HDL-c - Low Density Lipoprotein Cholesterol; High Density Lipoprotein Cholesterol. As associações encontradas na pesquisa sugerem que principalmente a mãe eleva as chances de o filho possuir um comportamento de saúde não saudável. Isso indica que, de todos os integrantes do convívio infantil, a mãe tem maior impacto na formação do estilo de vida da criança e consequentemente em sua saúde.

Um dos aspectos da saúde que a literatura refere como mais associado ao EdV é a nutrição e os comportamentos ligados a ela. Vários são os estudos que estabelecem a relação entre estilos de vida familiar com a obesidade infantil, havendo uma associação entre os estilos de vida de pais e filhos ${ }^{15,16}$. West et al. ${ }^{17}$ (2010) afirmam que o contexto familiar e os comportamentos dos pais têm um papel importante no desenvolvimento de sobrepeso e obesidade infantil. Em famílias que possuem maus hábitos alimentares existe uma relação entre a ingestão de gorduras e índice de massa corpórea dos pais e a obesidade de seus filhos, sugerindo a influência familiar no estado nutricional da criança ${ }^{16}$. A obesidade por si só tem repercussões a curto e a longo prazo e predispõe a criança a outras doenças crônicas como diabete melito, doenças cardiovasculares, doença hepática gordurosa não-alcoólica, além de diminuir a qualidade de vida como um todo ${ }^{16,18}$. O aumento 
das doenças não infecciosas em crianças são, em grande parte, decorrentes do estilo de vida dos pais.

Com base nas considerações feitas, resta-nos compreender um pouco mais sobre o conceito do termo 'Estilo de Vida'. Existem dois modelos propostos que conceituam o EdV: um epidemiológico e outro sociológico.

\subsection{Estilo de Vida Epidemiológico}

O primeiro modelo, apresentado pela área da saúde, tem a ver com os comportamentos de risco/proteção, ou seja, comportamentos associados estatisticamente à presença ou ausência de determinadas doenças. Esse modelo parte, portanto, de um paradigma epidemiológico.

Lalonde apud Colombo e Aguilar ${ }^{19}$ (1997) definiu EdV como "um conjunto de decisões individuais que afetam a saúde e sobre as quais se pode exercer certo grau de controle “ (p. 70). A OMS ${ }^{3}$ (1998) conceitua estilo de vida como um "padrão de comportamento que pode ter profundo efeito na saúde dos seres humanos e que está relacionado a aspectos que refletem as atitudes, valores e as oportunidades na vida das pessoas" (p.16).

Vários são os comportamentos de risco avaliados nos estudos relacionados com a saúde: o uso de medicações/suplementos sem prescrição médica ${ }^{20}$, cigarros $^{14}$, álcool $^{21}$, drogas $^{22}$ e bebidas com cafeína ${ }^{23}$. Além disso, o sedentarismo ${ }^{24,25}$, reduzida horas de sono noturno ${ }^{26,27}$, a presença de ansiedade ou depressão ${ }^{28}$, o não cuidado com a prevenção de acidentes, como o não uso de cinto de segurança ${ }^{29}$, o consumo

\footnotetext{
* Lalonde M. A new perspective on the health of Canadians: a working document. Ottawa, 1974.
} 
de dietas gordurosas, ricas em açúcares e pobres em fibras ${ }^{24,25,30}$ e o padrão de relacionamento familiar são incluídos na avaliação do $\mathrm{EdV}^{31}$. Dessa forma os indivíduos podem ser classificados como tendo um EdV saudável (com poucos comportamentos de risco à saúde) ou não saudável (o oposto), segundo o paradigma epidemiológico.

A limitação desse paradigma de EdV é que busca unicamente conhecer comportamentos de risco visando intervir sobre eles. Ele não permite entender porque grupos de indivíduos agem de determinadas maneiras ou o que pensam sobre o mundo em que estão inseridos.

\subsection{Estilo de Vida Sociológico}

O segundo modelo foi proposto originalmente pela área da sociologia ${ }^{32}$ e teve por finalidade conhecer os tipos de comportamento do homem. Segundo essa área do conhecimento, os EdV definidos por Maia* apud Finotti (2009)

(...) prendem-se com práticas quotidianas e formas de consumo que envolvem escolhas particulares e identitárias em domínios tão díspares como habitação, a alimentação, os usos do corpo, o vestuário, a aparência, os hábitos de trabalho, o lazer, a religião, a arte, a organização do espaço e do tempo ou o convívio com os outros atores sociais.

As ciências econômicas, principalmente com o foco no marketing, acabaram por adotar essa abordagem de EdV com a finalidade de melhor compreender o comportamento humano quanto à compra e consumo.

\footnotetext{
* Maia RL. Dicionário de sociologia. Porto: Porto Editora, 2002, p. 19.
} 
No marketing, o tema foi proposto indiretamente pela primeira vez em meados da década de 1950 quando surgiu a segmentação de mercado, uma forma de dividilo em áreas menores baseadas em necessidade de consumo, características e comportamento do consumidor ${ }^{33}$. Entretanto, ganhou destaque na década de 1970 quando a técnica de análise multivariada permitiu classificar os consumidores com base nos aspectos demográficos e comportamentais. Com isso, foi possível para os pesquisadores do marketing identificar as tendências que influenciam a vida, trabalho e diversão dos consumidores ${ }^{34}$.

O tema foi primeiramente estudado por Wells e Tigert ${ }^{35} \mathrm{em}$ 1971. Segundo eles, o EdV é o modo de viver como reflexo das atividades, interesses e opiniões das pessoas. Na época, eles propuseram alguns exemplos de itens de atividades, interesses e opiniões dos consumidores sobre assuntos diversos com a intenção de conhecer o perfil de comportamento de compra e consumo.

Após a iniciativa, Wells e Tigert e vários outros pesquisadores procuraram conhecer o tema propondo definições diversas como as descritas a seguir.

$\operatorname{Cosmas}^{36}$ (1982) definiu EdV como a maneira de viver e gastar tempo e dinheiro. Vyncke ${ }^{37}$ (2002), Moreira et al..$^{38}$ (2003) e Finotti ${ }^{32}$ (2009) também adotaram essa definição em seus estudos de EdV.

Anderson e Golden (1984) apud Fournier ${ }^{39}$ et al. (1992) afirmam que o EdV é o comportamento dos indivíduos como representação da personalidade. Adicionalmente, tal comportamento tanto determina quanto é determinado pelo consumo.

Para American Marketing Association ${ }^{40}$ - AMA - (1988), o EdV é a forma com a qual o indivíduo lida diariamente com o seu psicológico e ambiente físico. É uma

\footnotetext{
* Anderson WT, Golden LL. Lifestyle and psychographics: a critical review and recommendation. Adv Consum Research, 1984;11:405-411.
} 
palavra que descreve os valores, as atitudes, opiniões e padrões de comportamento do consumo. É a maneira na qual as pessoas conduzem suas vidas, incluindo suas atividades, interesses e opiniões. Nota-se que a AMA aborda o conceito proposto por Wells e Tigert $^{35}$ em 1971.

Lastovicka $^{*}$ (1982) apud Holt ${ }^{41}$ (1997) define EdV como traços da personalidade expressos sob a forma de comportamentos.

Para Wei ${ }^{34}$ (1997), EdV são "preferências ou gostos compartilhados, em que as pessoas dividem um EdV como coletividade que de outra forma não têm identidade social e cultural" (p. 262).

Engel et al. ${ }^{42}$ (2000) reúnem as definições propostas por Wells e Tigert $^{35}$ em 1971 e por Cosmas ${ }^{36}$ em 1982. Para eles, o EdV é o padrão no qual o indivíduo vive e gasta tempo e dinheiro como reflexo das atividades, interesses e opiniões.

Sheth $^{43}$ (2001) define como o modo de viver das pessoas que é determinado por características individuais como genética, raça, gênero, idade e personalidade; pelo contexto pessoal como cultura, instituições e grupos de referência e também pelo valor pessoal e pelas necessidades e emoções. Assim, é possível compreender a variabilidade que o EdV tem durante o decorrer da vida das pessoas: quando jovem, a personalidade, contexto e valores pessoais possuem uma determinada característica, ao passo que quando o indivíduo adquire a maturidade possui outra.

Para Lewis e Littler ${ }^{44}$ (2001), o EdV é resultado da interação que acontece entre variáveis sociais e pessoais, como família e cultura, com início na infância. É também resultado da vida em sociedade que reflete no comportamento de consumo e que tem influência econômica.

\footnotetext{
* Lastovicka JL. On the validation of lifestyle trait: a review and illustration. JMR. 1982;19:126-138.
} 
Para Chaney ${ }^{*}(1996)$ apud Vyncke ${ }^{37}$ (2002) é o modo de agir das pessoas em relação ao que e porque fazem e qual o significado de tais atitudes para si e para os outros que define o EdV.

Seguindo esses conceitos, mesmo que não exista ainda um consenso sobre o tema, alguns pesquisadores ${ }^{34,37,45,46,47}$ aceitam que os EdV são as Atitudes,

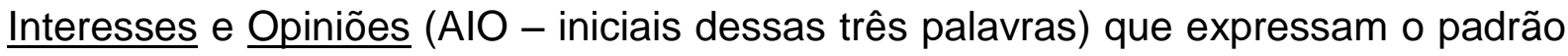
de vida das pessoas ${ }^{48,49}$ e esse foi o conceito adotado para esta pesquisa.

Para Valette-Florence ${ }^{\dagger}$ (1986) apud FINOTTI ${ }^{32}$ (2009), o EdV é dividido em três níveis: em um nível mais estável e seguro estão os valores pessoais; em um nível intermediário estão as atividades, interesses e opiniões que revelam os valores e que estão mais próximos do comportamento de compra; e em um nível periférico situa-se o conjunto de produtos adquiridos como reflexo dos dois níveis anteriores.

Existem alguns autores que enfatizam a importância de acrescentar ao AIO o V de $\underline{\text { Valores }}$ pessoais ${ }^{43,50}$ e que será comentado no tópico a seguir.

\subsubsection{Valores}

Valores são sentimentos sobre o que é importante em relação aos objetivos que a pessoa possui na vida ${ }^{43,51}$. Eles explicam com outra visão o motivo pelo qual as pessoas tomam decisões.

Existem três fontes específicas para se estudar os valores na pesquisa de Estilos de vida. A primeira delas é a Escala de Valores criada por Milton Rokeach -

\footnotetext{
* Chaney D. Lifestyles. London: Routledge, 1996.

${ }^{\dagger}$ Valette-Florence P. Les dérmaches de styles de vie: concepts, champs d'investigation et problèms actuels, Recherche et Applications en Marketing. Vol $1 \mathrm{~N}^{\circ} 1$ e 2, 1986.
} 
EVR. Para Milton Rokeach apud Sheth ${ }^{43^{*}}$ (2001), valor é definido como "uma crença duradoura de que um modo específico de conduta ou estado final de existência é pessoal ou socialmente preferível a um modo oposto ou contrário de conduta ou estado final da existência".

Ele identificou valores que são determinados pelas metas e maneiras de se comportar na vida. Eles são divididos em duas classes: os terminais e instrumentais. Os valores terminais são os objetivos buscados na vida. Os valores dessa classe são: uma vida próspera; uma vida excitante; um mundo em paz; igualdade; liberdade; felicidade; segurança nacional; prazer; salvação; reconhecimento social; amizade verdadeira; sabedoria; um mundo belo; segurança familiar; amor maduro; respeito próprio; senso de realização e harmonia interna. Os valores instrumentais são as maneiras de se comportar para atingir os valores terminais: ambição; mente aberta; capacidade; alegria; limpeza; coragem; generosidade; solicitude; honestidade; imaginação; independência; inteligência; racionalidade; amor; obediência; boas maneiras; responsabilidade e disciplina ${ }^{43}$. Os valores da EVR devem ser classificados por ordem de importância ${ }^{42}$.

A segunda fonte trata-se da Escala de Valores de Schwartz (EVS). Ela simplesmente é a forma simplificada da EVR, mas com enfoque em valores motivacionais em vez de instrumentais ou terminais. Pela teoria de Schwartz, valores são metas que os indivíduos seguem como princípios orientadores em suas vidas. A EVS é composta pelos seguintes valores: realização; autodireção; estimulação; benevolência; conformidade; segurança; um mundo de beleza; um mundo de paz; sabedoria e amor maduro ${ }^{42}$.

\footnotetext{
${ }^{*}$ Rokeach, M. The nature of human values. New York. The Free Press, 1973. v. 5, p. 57-58.
} 
A terceira fonte e a mais utilizada nos estudos de Estilos de Vida é a Lista de Valores $^{32}-\mathrm{LdV}$-, pois estão diretamente relacionados aos principais papeis assumidos na vida como casamento, ter filhos, trabalho, lazer, consumo diário entre outros $^{43}$. Em 1986, Kahle et al. ${ }^{50}$ desenvolveram uma LdV baseados na hierarquia das necessidades de Maslow e que são mais relevantes para o comportamento do consumidor. Ela é composta por nove valores terminais: respeito próprio; autorealização; segurança; sentimento de pertencer; estímulo; senso de realização; diversão; ser respeitado e relações calorosas com os outros ${ }^{51}$.

Os valores fazem parte da personalidade dos indivíduos e são estudados em situações de consumo, inclusive na escolha de produtos e marcas ${ }^{42}$. Estudar os valores permite que as pessoas sejam classificadas em grupos de EdV baseados naqueles de maior peso ${ }^{41}$.

Em síntese, o EdV de um indivíduo, portanto, é constituído por suas atitudes (que se referem a ações como trabalho, hobbie, eventos sociais, férias, entretenimento, clubes, comunidades, shopings, esportes etc. ou, por exemplo, uma ação como assistir a um meio de comunicação, comprar ou contar a um vizinho sobre um novo serviço), seus interesses (a importância que alguns eventos ou tópicos como família, lar, trabalho, comunidade, lazer, moda, alimentação, mídia etc. têm para a vida da pessoa), suas opiniões (são respostas faladas ou escritas que uma pessoa dá quando algumas questões são levantadas. Tais questões podem ser sobre si mesmo ou sobre a sociedade, política, trabalho, economia, educação, produtos, futuro, cultura etc.) e finalmente seus valores (definidos como os objetivos da vida que guiam a forma de viver das pessoas) ${ }^{37,42,43}$. Os valores pessoais afetam o comportamento e também é determinante do $\mathrm{EdV}^{37}$. 
O interesse que a abordagem sociológica traz para esta pesquisa é compreender o EdV materno segundo as atividades, interesses, opiniões e valores que estão por trás dos comportamentos de risco passados aos pré-escolares. Entretanto, resta-nos averiguar questões como 'o que mede o estilo de vida?' 'Qual a associação entre estilos de vida e as condições de saúde e nutrição?' 'Quais as variáveis ou combinação de variáveis que melhor caracterizam o estilo de vida?'

A seguir, uma breve descrição das etapas de elaboração de instrumentos de medição de aspectos subjetivos como proposta de pesquisa.

\subsection{Elaboração e validação de questionário}

O estado de saúde geral das pessoas é avaliado por medidas objetivas e subjetivas $^{52}$. Essas últimas avaliam aspectos de personalidade, comportamentos e processos mentais. Para propor medida subjetiva desses aspectos, como é o caso de descrever EdV, é necessário passar por uma técnica operacional quantitativa chamada psicografia ${ }^{42}$. Reichenheim e Moraes $^{53}$ (2007) propõem algumas etapas que devem ser cumpridas ao se elaborar instrumentos de aferição dos aspectos subjetivos das pessoas. Cada tópico a seguir diz respeito à ordem cronológica de etapas para sua elaboração e validação. 


\subsubsection{Definição do construto.}

Construto é o nome dado a um aspecto psicológico, abstrato, não quantificável, mas que pode ser identificado através de comportamentos ${ }^{52,54,55}$. Por exemplo, inteligência é algo não mensurável diretamente, mas que pode ser medido através de respostas objetivas.

O primeiro passo ao se desenvolver questionários é realizar um levantamento bibliográfico em busca da melhor definição do construto que se quer avaliar ${ }^{53,56}$. As limitações dessa etapa incluem a dificuldade de obter toda a amplitude de sentido do construto e a dificuldade em formular hipóteses claras e adequadas devido à variedade de conceitos ${ }^{57}$.

\subsubsection{Formulação dos itens}

Tendo-se a melhor definição do construto, o próximo passo é a operacionalização do conceito expresso sob a forma de itens ${ }^{56}$. O método mais simples para obter itens que comporão o questionário é através de pesquisa bibliográfica, em que se avalia os itens dos questionários existentes e seleciona-se os melhores. Outro método é através da realização de grupos focais ${ }^{53,56,58} \mathrm{em}$ que é solicitado a uma pequena amostra da população-alvo a que se destina o questionário que elabore frases sobre o que pensam e opinam sobre o construto ${ }^{53,56}$. Opiniões de especialistas no assunto e experiência do próprio pesquisador são 
outros métodos de se obter e formular itens ${ }^{56}$. O objetivo dessa etapa é adquirir um conjunto bem completo de itens a fim de garantir a validade de conteúdo, mas não tão extenso a ponto de impossibilitar a sua aplicação junto à população ${ }^{53}$.

\subsubsection{Adequação semântica dos itens}

Após a elaboração dos itens, segue a terceira etapa que é a da adequação semântica. Para evitar ambigüidade e vários significados, cada item deve ser lido e observado se está escrito de forma objetiva, clara, simples e curta. O item deve ser diferente dos demais que cobrem o mesmo domínio, ter linguagem variada e coesa com a cultura da população-alvo a fim de não causar monotonia, cansaço ou aborrecimento ao entrevistado ${ }^{56,59}$. Além disso, ele deve ter um número reduzido de sílabas, como recomenda Holden ${ }^{*}$ apud Streiner e Norman ${ }^{60}$ (2008) e ser curto, nem tão pequeno a ponto de perder informação e nem tão longo a ponto de causar esquecimento das primeiras palavras. Ele deve passar uma única idéia de um comportamento e uma ação clara e precisa. Quanto à ordenação, é preferível que sejam intercalados quando tiverem várias intensidades e que os mais constrangedores sejam locados no final do questionário ${ }^{53,59}$.

\footnotetext{
* Holden RR, Fekken GC, Jackson DN. Structured personality test item characteristics and validity. J Res Pers. 1985;19:386-94.
} 


\subsubsection{Escalonamento de respostas}

Após a adequação semântica, é necessário formular as opções de resposta aos itens. São várias e elas podem ser categóricas, ordinais ou intervaladas ou estar sob a forma de escalas visuais analógicas, adjetivais, Likert, diferencial semântica entre outras $^{53,60}$. Quando as escalas forem do tipo categórica, é preferível que o número de respostas varie de cinco a nove para que o entrevistado não tenha dificuldade em dar uma resposta e para que não haja perda de informação ${ }^{60}$.

\subsubsection{Realização do pré-teste}

É necessária a realização de um pré-teste após a elaboração dos itens e das opções de resposta a fim de avaliar a aceitabilidade, clareza $^{7}$, entendimento ${ }^{53}$ e redução do número de itens ${ }^{61}$. O questionário seria aplicado, por exemplo, em uma pequena quantidade de pessoas, geralmente $\operatorname{trinta}^{56}$ e que não fazem parte ${ }^{62}$, mas que tenham características parecidas com a da amostra-alvo. Após a aplicação, os entrevistados devem apontar as principais dúvidas quanto às instruções, perguntas e opções de resposta ou qualquer outro aspecto que tenha ficado confuso no questionário $^{63}$. Outros autores recomendam que o entrevistado indique o nível de entendimento do questionário respondendo 'eu não entendi nada', 'eu entendi um pouco', 'eu entendi quase tudo, mas tive algumas dúvidas' ou 'eu entendi tudo completamente ${ }^{64}$. 


\subsubsection{Consolidação do instrumento}

A consolidação do instrumento consiste num procedimento de constatar o cumprimento de três etapas: dimensionalidade, confiabilidade, validade.

\subsubsection{Dimensionalidade}

A primeira é a confirmação da dimensionalidade do instrumento. Nela, avalia-se se o questionário aborda apenas um aspecto ou mais que um. Portanto, é o momento onde pode ser dito se o questionário é homogêneo ou heterogêneo ${ }^{55}$. A dimensionalidade do instrumento é avaliada através da análise fatorial exploratória ${ }^{53}$.

\subsubsection{Confiabilidade}

A segunda etapa abrange análises de confiabilidade ${ }^{53}$. Confiabilidade é a característica que o questionário deve ter que é de medir sem erros. As medidas estatísticas para se obter a confiabilidade do instrumento mais utilizadas são: consistência interna; estabilidade temporal ou reprodutibilidade intra ou interobservador. 
A consistência interna reflete o nível de correlação entre os itens de um questionário. Para correlacionarem com o construto de interesse, também devem se correlacionar entre $\mathrm{si}^{55}$ e em qualquer aplicação do teste ${ }^{57}$. A consistência interna é analisada através da prova das metades e do alfa de Cronbach, o indicador mais utilizado ${ }^{65}$ e o que aqui será comentado. $O$ alfa de Cronbach é utilizado quando apenas uma aplicação do questionário é feita ${ }^{52,57,60}$ e quando o questionário tem mais que duas opções de resposta ${ }^{65}$. O valor do alfa representa a média de correlações entre todos os itens do questionário ${ }^{7,60}$ e é influenciado pela quantidade que o compõ $e^{55}$, pelo tamanho da amostra ${ }^{7}$ e "pela saturação do primeiro fator em uma análise fatorial de um grupo de itens" ${ }^{\prime 65}$ (p. 43). O alfa varia de zero a um e a faixa de valores que o melhor representa situa-se entre 0,7 e 0,9. Uma limitação no uso do alfa é que, por ser obtido por apenas uma aplicação, ele não leva em conta variações que acontecem no dia-a-dia do entrevistado, nem o modo com o qual o observador aplica o questionário ${ }^{60}$.

Estabilidade temporal é outra técnica de se obter a exatidão do teste ${ }^{57}$ e referese à variação dos escores de um questionário quando aplicado à mesma pessoa em tempos diferentes. Ela é realizada através do teste-reteste do questionário ${ }^{66}$, ou seja, sua versão final é aplicada uma vez e, dentro de um intervalo de, aproximadamente, dois a quatorze dias ${ }^{55,65}$, a fim de se reduzir a possibilidade de grandes mudanças, se faz uma reaplicação do questionário às mesmas pessoas. Essa reaplicação pode ser feita pelo mesmo pesquisador (intra-observador) ou por pesquisador diferente (inter-observador). Após a aplicação do questionário no teste e reteste, calcula-se o coeficiente de correlação de cada item o qual avalia a concordância dos escores nos dois momentos ${ }^{55,66,67}$. 


\subsubsection{Validade}

A terceira etapa é estabelecer a validade ${ }^{53}$. Muitos autores fazem referência ao termo validade de forma abstrata e nenhum consegue concretamente dizer quando um instrumento é válido e nem o que significa o valor dos escores obtidos como resposta. Um teste é válido se mede o que deve medir ${ }^{52,55,65,66,68}$.

Existem mais de trinta tipos de validade ${ }^{54}$. Entretanto, as técnicas mais utilizadas para demonstrar a validade de instrumentos são reduzidas a três categorias: validade de conteúdo, critério e construto ${ }^{52,57}$.

Validade de conteúdo é o nome dado à avaliação feita sobre cada item quanto à representatividade de seu conteúdo em relação ao construto que se quer medirr ${ }^{52,66}$. Durante a revisão da literatura ${ }^{55,69}$, procura-se obter a maior quantidade possível de itens a fim de possuir um universo finito, mas com conteúdo abrangente ${ }^{54,57,70}$.

Validade de critério é um tipo de validade em que se correlaciona um critério externo com as pontuações obtidas como resultados do questionário ${ }^{52,54,56,57,69,70}$. Geralmente o critério externo é um exame clínico-laboratorial ou avaliação tida como padrão-ouro de diagnóstico já existente ${ }^{55,63,65,66,68}$. Essa validade é utilizada quando um novo instrumento mais simples e conveniente é desenvolvido em substituição a um mais extenso ${ }^{65,68}$.

Validade de construto é a interpretação da medida de algum atributo ou qualidade que não é operacionalmente definida ${ }^{54,70}$. É a forma de verificar a representação do construto sob a forma de comportamentos ${ }^{57}$. Essa validade é realizada por meio de medidas como análise de regressão $0^{63}$, comparação dos escores obtidos no questionário com medidas antropométricas ou 
laboratoriais ${ }^{63,64,66,68}$, comparação dos resultados obtidos com o questionário e um grupo controle, análise fatorial ${ }^{52,65,66}$, análise da consistência interna, a análise por hipótese, curva de informação da teoria de resposta ao item, além do "falsete estatístico do erro de estimação da teoria clássica dos itens"66 (p. 21).

\subsection{Análise fatorial}

A análise fatorial é uma técnica estatística utilizada para resumir os dados ou as variáveis de um estudo, de forma que a quantidade remanescente explique a variabilidade dos dados originais ${ }^{60}$. Ela permite determinar se as variáveis medidas podem ser explicadas por um pequeno número de fatores ${ }^{32}$. Para entendimento, as variáveis serão chamadas de itens e o conjunto de variáveis de fatores.

Primeiramente, é necessário saber se a análise fatorial pode ser realizada. Para isso, outros testes estatísticos avaliam se há correlação entre as variáveis de uma matriz. Para acontecer a análise fatorial, é preciso que um conjunto de variáveis tenha alta correlação entre si e baixa correlação com as variáveis de outro conjunto ${ }^{60}$.

Havendo correlação, procede-se a análise fatorial em que são obtidos os fatores mais significativos. Geralmente, o critério para a escolha dos fatores é ficar com aqueles com autovalor (quantidade de variância que cada fator tem da variância total) maior que um ou o número de fatores onde a curva, no gráfico de barreira, passa a apresentar menor inclinação ${ }^{60}$. 
Após ter definido com quantos fatores ficar, olha-se o valor de carga (correlação) de cada item dentro de cada fator para decidir quais serão os itens pertencentes a cada fator escolhido. Em alguns casos, realiza-se a rotação dos fatores para corrigir aspectos de pertença dos itens aos próprios fatores. Esse passo leva à interpretação subjetiva dos fatores ${ }^{60}$. 


\section{Justificativa}

O EdV materno é um determinante importante da saúde das crianças. É preciso saber em quais dimensões, além das comportamentais, ele afeta a saúde da criança pré-escolar, uma vez que esta está sujeita às influências ambientais e de terceiros. Entretanto, não há instrumento de medida a nível nacional que descreva EdV materno segundo o conceito aqui adotado e que posteriormente possa ser utilizado em associações com aspectos nutricionais da criança. Seu melhor conhecimento poderá implicar numa maior capacidade de alterá-lo através de intervenções. 


\section{Objetivo}

Elaborar e validar um questionário para descrever o EdV de mães de crianças em idade pré-escolar. 


\section{Métodos}

\subsection{Desenho do estudo}

Entre janeiro de 2010 a março de 2011 foi realizado um estudo transversal com mães de crianças em idade pré-escolar, três a cinco anos, moradoras dos subdistritos Butantã, Morumbi, Raposo Tavares, Rio Pequeno e Vila Sônia, na Região Sudoeste do município de São Paulo, SP. O protocolo de pesquisa foi aprovado pelo Comitê de Ética e Pesquisa do Hospital das Clínicas da Faculdade de Medicina da Universidade de São Paulo.

\subsection{Variáveis coletadas e instrumento}

Em relação à mãe da criança foram coletados dados sobre:

- Idade em anos, sendo a diferença entre a data da entrevista e a data de nascimento;

- Classe econômica: avaliada através do Critério de Classificação Econômica Brasil $^{71}$ de 2007 (Anexo A). A avaliação foi feita de acordo com um sistema de pontos dividido em cinco categorias relacionadas ao número de bens que a família possui em casa. O pesquisador de campo treinado marcava com um " $\mathrm{x}$ " sobre 0 número correspondente ao número de itens ou bens que a mãe possuía em casa. 
Por fim, a pontuação adquirida nessa avaliação foi somada à pontuação do grau de instrução, o que permitiu classificar a família economicamente. Optou-se por agrupar as classes A1 e A2 em apenas classe A e assim sucessivamente até que ficássemos com cinco classes: A, B, C, D e E. A classe A é aquela com maior poder aquisitivo e a classe E é aquela com menor poder aquisitivo. Os bens avaliados para classificar a mãe economicamente foram: televisão em cores, rádio, banheiro, automóvel, empregada mensalista, máquina de lavar, videocassete e/ou aparelho de DVD, geladeira, freezer (aparelho independente ou parte da geladeira duplex) ${ }^{71}$.

- Grau de instrução: também foi analisado através do Critério de Classificação Econômica Brasil e dividido em cinco categorias: analfabeto, primário completo, ensino fundamental completo, ensino médio completo, ensino superior completo ${ }^{71}$. Para analisar essa questão, foi perguntado à mãe até qual série estudou e assim era marcado sobre o item correspondente.

- Estado civil: foi questionado através de cinco categorias: solteiro, casado, separado, divorciado ou viúvo.

\subsection{Construção do Instrumento}

Foi realizada uma busca bibliográfica a fim de encontrar trabalhos de validação de questionários de EdV e que abordassem a mesma definição aqui adotada. Primeiramente, foram utilizados três instrumentos (Anexo B): um para avaliar valores e estilos de vida; uma escala para mensurar a auto-imagem e imagem de produtos, e frases de $\mathrm{AlO}^{43}$. Esses três instrumentos foram submetidos a um primeiro pré-teste 
(PRÉ-TESTE UM) com doze mães de crianças em idade pré-escolar de diferentes classes sociais. Para o primeiro e terceiro instrumentos as opções de resposta utilizadas foram: 'discordo totalmente; discordo em termos; concordo totalmente ou concordo em termos'.

O PRÉ-TESTE UM demonstrou a necessidade de adaptação cultural e validade de conteúdo dos questionários, bem como adequação das opções de resposta. Quatro profissionais, um especialista em marketing, dois médicos pediatras e um nutricionista modificaram-no para adequar os termos à cultura brasileira. A escala para mensurar a auto-imagem e imagem de produtos foi eliminada por ser de difícil preenchimento por mães com poucos anos de estudo e o questionário de estilo de vida e valores foi eliminado pelo fato de as questões não possuírem qualquer relação com a cultura brasileira. Dos três instrumentos iniciais propostos, somente as frases de AIO selecionadas foram utilizadas, porém com novas opções de resposta como 'discordo totalmente, discordo, não concordo e nem discordo, concordo ou concordo totalmente', e um questionário sobre valores pessoais foi acrescentado por um especialista em marketing, tendo como opções de resposta 'nada importante, pouco importante, importante, muito importante ou totalmente importante'.

Para verificar a clareza, o questionário em sua segunda versão (com frases de AIO e de valores pessoais - Anexo C) foi aplicado no PRÉ-TESTE DOIS a dez mães, às quais se solicitou que manifestassem se cada questão não estivesse clara ou se tivessem dificuldade em dar alguma resposta. Nenhuma mãe se manifestou.

O questionário foi, então, submetido a um ESTUDO PILOTO com cinquenta mães de crianças em idade pré-escolar de uma escola pública na Vila Sônia e uma escola privada no Butantã. Nessa fase, quatro pesquisadores de campo treinados, 
estudantes do quarto ano de Nutrição, aplicaram o questionário e dentro de um intervalo de, aproximadamente, quinze dias um RETESTE foi realizado, dessa vez feito pela pesquisadora principal deste estudo. Durante o estudo piloto foi solicitado que as mães se manifestassem em caso de dúvidas respondendo ao final do questionário 'Eu não entendi nada', 'Eu entendi um pouco', 'Eu entendi mais ou menos', 'Eu entendi quase tudo, mas tive algumas dúvidas' ou 'Eu entendi tudo completamente'. Foi notada a necessidade de adaptação semântica dos itens. Um professor de português os alterou, atento a manter o sentido original. Assim se formou a versão final do questionário (Anexo D) a qual foi submetida ao PRÉ-TESTE TRÊS com seis mães. Dessas, nenhuma se manifestou quanto a aspectos confusos ou dificuldades em dar reposta. De todas as mães que participaram dos PRÉTESTES, nenhuma participou da pesquisa final. Antes de realizá-la, os pesquisadores de campo foram novamente treinados.

\subsection{Amostragem}

O tamanho da amostra foi calculado com base num $\alpha$ de 0,05 e um $\beta$ de 0,10 e coeficiente de correlação de 0,5 , sendo necessários 38 (trinta e oito) indivíduos para validação do questionário ${ }^{72}$. Entretanto, para análise com outros desfechos (morbidade no último ano, alimentação, medidas antropométricas e atividade física da criança), foram coletados dados de 153 (cento e cinquenta e três) mães na primeira entrevista das quais 102 (cento e duas) foram submetidas ao reteste. 
A população-alvo foram todas as mães de crianças pré-escolares do distrito de Saúde do Butantã da prefeitura da cidade de São Paulo. A unidade amostral foi o binômio 'mãe-criança'.

Selecionou-se uma amostra probabilística aleatória estratificada proporcional, com dois estratos ('escola' e 'criança'), a qual foi considerada na análise estatística. A grelha de amostragem foi a lista total de pré-escolas públicas e privadas cadastradas na diretorial regional de ensino do distrito de saúde do Butantã, região sudoeste do município de São Paulo (cinquenta e nove escolas, sendo trinta e sete particulares e vinte e duas públicas).

O critério de inclusão foi que as crianças estivessem devidamente matriculadas e regulares nas séries de primeiro e segundo estágio. O critério para exclusão foi a criança possuir alguma deficiência neurológica.

Primeiramente as escolas foram sorteadas de forma proporcional à quantidade de crianças por subdistrito. Um contato com o diretor escolar foi realizado, após o sorteio das escolas, para obtenção de consentimento de pesquisa. Para as escolas públicas, foi necessário obter uma autorização de pesquisa com o diretor regional de ensino. Em seguida, foi sorteado o número de crianças necessário por escola e vários sorteios foram realizados até que se completasse a quantidade final da amostra. Bilhetes informativos sobre a pesquisa foram colados nas agendas das crianças sorteadas destinados às mães. Aquelas que concordavam em participar deixavam nome e telefone e um contato era feito pelo pesquisador de campo treinado para as atividades, o qual ia à casa realizar a entrevista. Antes de iniciá-la, a mãe lia e, em concordância com a pesquisa, assinava um Termo de Consentimento Livre e Esclarecido - Anexo E. 
A entrevista foi realizada em ambiente domiciliar e escolar sem influência de terceiros. Dentro de um intervalo de quinze dias, um RETESTE foi aplicado pela pesquisadora principal deste trabalho.

\subsection{Análises estatísticas}

As variáveis categóricas foram descritas segundo as suas freqüências em porcentagens e intervalos de $95 \%$ de confiança. A idade das mães foi descrita segundo média e desvio padrão. A confiabilidade do instrumento foi avaliada por duas medidas estatísticas: pela consistência interna através do alfa de Cronbach, tendo como ponto de corte um valor maior que 0.7 e pela estabilidade temporal (comparando as respostas na primeira aplicação com as do reteste) através do coeficiente de correlação pairwise interobservador maior que $0.5^{60}$.

A dimensionalidade do instrumento foi estudada pela análise fatorial que buscou agrupar os itens em domínios que mais descrevem os EdV.

Inicialmente procedeu-se o teste de esfericidade de Bartlett para averiguar se a matriz de correlação é adequada para se proceder a análise fatorial. Para tanto é preciso avaliar se se trata de uma matriz de identidade. Em caso positivo ("p" $>0,05$ ), a análise fatorial não é recomendada. Uma matriz de identidade implica que na população as variáveis não apresentam qualquer correlação entre si.

Depois se realizou a medida de adequação amostral de Kaiser-Meyer-Olkin. Ela indica se os padrões de correlação são relativamente compactos, pouco dispersos, e, portanto se a análise fatorial será capaz de produzir fatores diferentes e 
confiáveis. Espera-se que seu resultado seja maior que 0,6 para confirmar que a análise fatorial é possível.

Em seguida foram avaliados quantos fatores seriam considerados, através do "gráfico de barreira", usando como critério o número de fatores onde a curva passava a apresentar menor inclinação.

Posteriormente foi realizada uma rotação oblíqua para obtenção dos valores de carga de cada item.

Optou-se por incluir somente os itens com valores de carga maiores que 0,40 ou menores que $-0,40$, a partir da fórmula $5,152 /(\mathrm{N}-2)^{1 / 2}$, conforme sugerido por Norman e Streiner ${ }^{73}$ (2003).

Os itens foram atribuídos ao fator onde tiveram maior valor de carga.

A terceira e última etapa foi a interpretação subjetiva de cada fator. Eles foram denominados a partir dos seus itens com maior valor de carga.

Foi utilizado o pacote estatístico STATA versão 10.0. 


\section{Resultados}

Um total de cento e cinquenta e três mães participou da primeira entrevista e dessas cento e duas participaram do reteste. A média de idade e desvio padrão foi de 32,9 anos e 6,45 anos, respectivamente. A tabela 1 mostra a proveniência escolar das crianças, filhas das participantes do estudo e a tabela 2 mostra as características da amostra. As mães pertenciam a todas as classes sociais, níveis de escolaridade e estado civil, sendo que as mais freqüentes eram aquelas de classe C, com ensino médio completo e casadas.

Tabela 1 - Número e proporção de tipos e região das escolas de préescolares, Região Oeste, São Paulo, SP - 2011

\begin{tabular}{lcc}
\hline & N & $\%$ \\
\hline \multicolumn{1}{c}{ TIPO DE ESCOLA } & 43 & \\
Particular & 110 & 28,1 \\
Pública & & 71,9 \\
$\quad$ REGIÃO DA ESCOLA & 34 & 22,2 \\
Raposo Tavares & 24 & 15,7 \\
Rio Pequeno & 30 & 19,6 \\
Vila Sônia & 29 & 19,0 \\
Butantã & 36 & 23,5 \\
Morumbi & & \\
\hline
\end{tabular}


Tabela 2 - Características da amostra segundo número, proporção e intervalo de confiança da classificação econômica, grau de instrução e estado civil de mães de pré-escolares, Região Sudoeste, São Paulo, SP - 2011

\begin{tabular}{lccc}
\hline & N & $\%$ & IC (95\%) \\
\hline CLASSIFICAÇÃO ECONÔMICA & & & \\
A & 18 & 11,8 & 7,1 a 18,0 \\
B & 47 & 30,7 & 23,5 a 38,7 \\
C & 76 & 49,7 & 41,5 a 57,9 \\
D & 10 & 6,5 & 3,2 a 11,7 \\
E & 2 & 1,3 & 0,2 a 4,6 \\
$\quad$ GRAU DE INSTRUÇÃO & & & \\
Analfabeta & 3 & 2,0 & 0,4 a 5,6 \\
Primário completo & 26 & 17,0 & 11,4 a 23,9 \\
Fundamental completo & 41 & 26,7 & 20,0 a 34,5 \\
Ensino médio completo & 50 & 32,7 & 25,3 a 40,7 \\
Superior completo & 33 & 21,6 & 15,3 a 28,9 \\
$\quad$ ESTADO CIVIL & & & \\
Solteira & 39 & 25,5 & 18,8 a 33,2 \\
Casada & 96 & 62,7 & 54,6 a 70,4 \\
Divorciada & 6 & 3,9 & 1,5 a 8,3 \\
Separada & 10 & 6,5 & 3,2 a 11,7 \\
Viúva & 2 & 1,4 & 0,2 a 4,6 \\
\hline
\end{tabular}

A distribuição de classes econômicas desta pesquisa apresentada na tabela 3 assemelhou-se à encontrada no Município de São Paulo pela $A B E P^{71}$ em 2007, somente nas classes $B, C$ e E, o que mostra a mudança no perfil econômico da população da região sudoeste, com redução do número de famílias com baixo poder aquisitivo e aumento do número de famílias com maior poder aquisitivo.

Tabela 3 - Proporção de famílias pertencentes às classes econômicas A, B, C, D e E no município de São Paulo em 2007 e em cinco subsdistritos da Região Sudoeste do mesmo município em 2010/2011, Região Sudoeste, São Paulo, SP - 2011

Classes Município de São Paulo 2007 (\%) Região Sudoeste 2010 (\%)

\begin{tabular}{ccc} 
A & 5,1 & 11,8 \\
B & 29,6 & 30,7 \\
C & 43,9 & 49,7 \\
D & 20,7 & 6,5 \\
E & 2,1 & 1,3 \\
\hline
\end{tabular}

FONTE: ABEP ${ }^{71}, 2007$. 
O questionário continha cinquenta e três itens e abordava assuntos sobre valores, atividades, interesses e opiniões das entrevistadas. O valor do alfa de Cronbach na versão aplicada no estudo piloto foi de 0,81 , enquanto que o valor na versão final do instrumento foi de 0,83 .

Os coeficientes de correlação pairwise no estudo piloto e na última aplicação do instrumento estão na tabela 4. Foi calculado coeficiente de correlação para cento e duas entrevistas. Nota-se melhora dos valores do alfa e dos coeficientes da maioria dos itens após adequação semântica e cultural.

Tabela 4 - Coeficiente de correlação pairwise dos itens do questionário no estudo piloto e na pesquisa final, Região Sudoeste, São Paulo, SP - 2011

\begin{tabular}{cccccccccccc}
\hline Item & Piloto & Final & Item & Piloto & Final & Item & Piloto & Final & Item & Piloto & Final \\
\hline 1 & 1,00 & 0,74 & 15 & 0,54 & 0,54 & 29 & 0,71 & 0,82 & 43 & 0,46 & 0,56 \\
2 & 0,49 & 0,72 & 16 & 0,60 & 0,63 & 30 & 0,56 & 0,79 & 44 & 0,36 & 0,82 \\
3 & 1,00 & 0,69 & 17 & 0,27 & 0,72 & 31 & 0,41 & 0,52 & 45 & 0,63 & 0,61 \\
4 & 0,32 & 0,67 & 18 & 0,69 & 0,76 & 32 & 0,21 & 0,61 & 46 & 0,36 & 0,65 \\
5 & 0,82 & 0,82 & 19 & 0,47 & 0,84 & 33 & 0,39 & 0,50 & 47 & $-0,02$ & 0,70 \\
6 & 0,23 & 0,65 & 20 & 0,17 & 0,54 & 34 & 0,47 & 0,59 & 48 & 0,31 & 0,52 \\
7 & 0,76 & 0,98 & 21 & 0,57 & 0,78 & 35 & 0,39 & 0,54 & 49 & 0,15 & 0,69 \\
8 & 0,58 & 0,69 & 22 & 0,31 & 0,79 & 36 & 0,40 & 0,72 & 50 & 0,46 & 0,70 \\
9 & 0,68 & 0,80 & 23 & 0,70 & 0,85 & 37 & 0,08 & 0,58 & 51 & 0,53 & 0,67 \\
10 & 0,25 & 0,76 & 24 & 0,74 & 0,59 & 38 & 0,36 & 0,51 & 52 & 0,69 & 0,57 \\
11 & 0,73 & 0,82 & 25 & 0,65 & 0,82 & 39 & 0,68 & 0,58 & 53 & 0,48 & 0,79 \\
12 & 0,58 & 0,61 & 26 & 0,53 & 0,84 & 40 & 0,54 & 0,71 & & & \\
13 & 0,54 & 0,75 & 27 & 0,44 & 0,65 & 41 & 0,38 & 0,50 & & & \\
14 & 0,16 & 0,73 & 28 & 0,67 & 0,70 & 42 & 0,39 & 0,66 & & &
\end{tabular}

O teste de esfericidade de Bartlett produziu um $\mathrm{p}<0,001$ e a medida de adequação amostral de Kaiser-Meyer-Olkin (KMO) foi de 0,71. Ambos os resultados confirmam que a matriz de dados pode ser submetida à análise fatorial.

A análise fatorial permitiu identificar cinquenta e três fatores de Estilos de Vida como é mostrado na tabela 5. Desses, nove obtiveram um autovalor maior que um. 
Entretanto, o gráfico 1 mostra que os sete primeiros componentes são capazes de explicar o construto EdV.

Tabela 5 - Autovalor, proporção e \% acumulado dos fatores do questionário de Estilo de Vida, Região Sudoeste, São Paulo, SP -2011

\begin{tabular}{|c|c|c|c|c|c|c|c|}
\hline Itens & Autovalor & Proporção & $\%$ Acumulado & Itens & Autovalor & Proporção & $\%$ Acumulado \\
\hline 1 & 8,10496 & 0,2744 & $27,44 \%$ & 28 & 0,14495 & 0,0000 & $109,93 \%$ \\
\hline 2 & 3,23208 & 0,4267 & $38,38 \%$ & 29 & 0,11095 & 0,0000 & $110,31 \%$ \\
\hline 3 & 2,80534 & 0,0950 & $47,87 \%$ & 30 & 0,10333 & 0,0000 & $110,66 \%$ \\
\hline 4 & 2,2844 & 0,0773 & $55,61 \%$ & 31 & 0,08505 & 0,0000 & $110,94 \%$ \\
\hline 5 & 2,02234 & 0,0685 & $62,45 \%$ & 32 & 0,07389 & 0,0000 & $111,19 \%$ \\
\hline 6 & 1,5422 & 0,0522 & $67,67 \%$ & 33 & 0,01088 & 0,0000 & $111,23 \%$ \\
\hline 7 & 1,17758 & 0,0004 & $71,66 \%$ & 34 & $-0,00783$ & $-0,0003$ & $111,21 \%$ \\
\hline 8 & 1,15912 & 0,0004 & $75,58 \%$ & 35 & $-0,03593$ & $-0,0012$ & $111,08 \%$ \\
\hline 9 & 1,06193 & 0,0004 & $79,18 \%$ & 36 & $-0,04617$ & $-0,0016$ & $110,93 \%$ \\
\hline 10 & 0,93926 & 0,0003 & $82,36 \%$ & 37 & $-0,06559$ & $-0,0022$ & $110,71 \%$ \\
\hline 11 & 0,89199 & 0,0003 & $85,38 \%$ & 38 & $-0,07562$ & $-0,0026$ & $110,45 \%$ \\
\hline 12 & 0,82117 & 0,0003 & $88,16 \%$ & 39 & $-0,09239$ & $-0,0031$ & $110,14 \%$ \\
\hline 13 & 0,77382 & 0,0003 & $90,78 \%$ & 40 & $-0,10677$ & $-0,0036$ & $109,78 \%$ \\
\hline 14 & 0,64365 & 0,0002 & $92,96 \%$ & 41 & $-0,13547$ & $-0,0046$ & $109,32 \%$ \\
\hline 15 & 0,58891 & 0,0002 & $94,95 \%$ & 42 & $-0,14403$ & $-0,0049$ & $108,83 \%$ \\
\hline 16 & 0,58022 & 0,0002 & $96,91 \%$ & 43 & $-0,16079$ & $-0,0054$ & $108,28 \%$ \\
\hline 17 & 0,51825 & 0,0002 & $98,67 \%$ & 44 & $-0,18073$ & $-0,0061$ & $107,67 \%$ \\
\hline 18 & 0,51327 & 0,0002 & $100,40 \%$ & 45 & $-0,18946$ & $-0,0064$ & $107,03 \%$ \\
\hline 19 & 0,4392 & 0,0001 & $101,87 \%$ & 46 & $-0,19263$ & $-0,0065$ & $106,38 \%$ \\
\hline 20 & 0,40278 & 0,0001 & $103,23 \%$ & 47 & $-0,21893$ & $-0,0074$ & $105,64 \%$ \\
\hline 21 & 0,37736 & 0,0001 & $104,51 \%$ & 48 & $-0,23408$ & $-0,0079$ & $104,85 \%$ \\
\hline 22 & 0,37156 & 0,0001 & $105,77 \%$ & 49 & $-0,25156$ & $-0,0085$ & $103,99 \%$ \\
\hline 23 & 0,29065 & 0,0001 & $106,75 \%$ & 50 & $-0,27148$ & $-0,0092$ & $103,08 \%$ \\
\hline 24 & 0,2266 & 0,0001 & $107,52 \%$ & 51 & $-0,29306$ & $-0,0099$ & $102,08 \%$ \\
\hline 25 & 0,21276 & 0,0001 & $108,24 \%$ & 52 & $-0,29736$ & $-0,0101$ & $101,08 \%$ \\
\hline 26 & 0,18062 & 0,0001 & $108,85 \%$ & 53 & $-0,31806$ & - 0,0108 & $100,00 \%$ \\
\hline 27 & 0,17413 & 0,0001 & $109,44 \%$ & & & & \\
\hline
\end{tabular}


Gráfico 1 - Gráfico de Barreira, segundo os eigenvalues (autovalores) de cada fator do questionário de estilo de vida AIOV, Região Sudoeste, São Paulo, SP - 2011

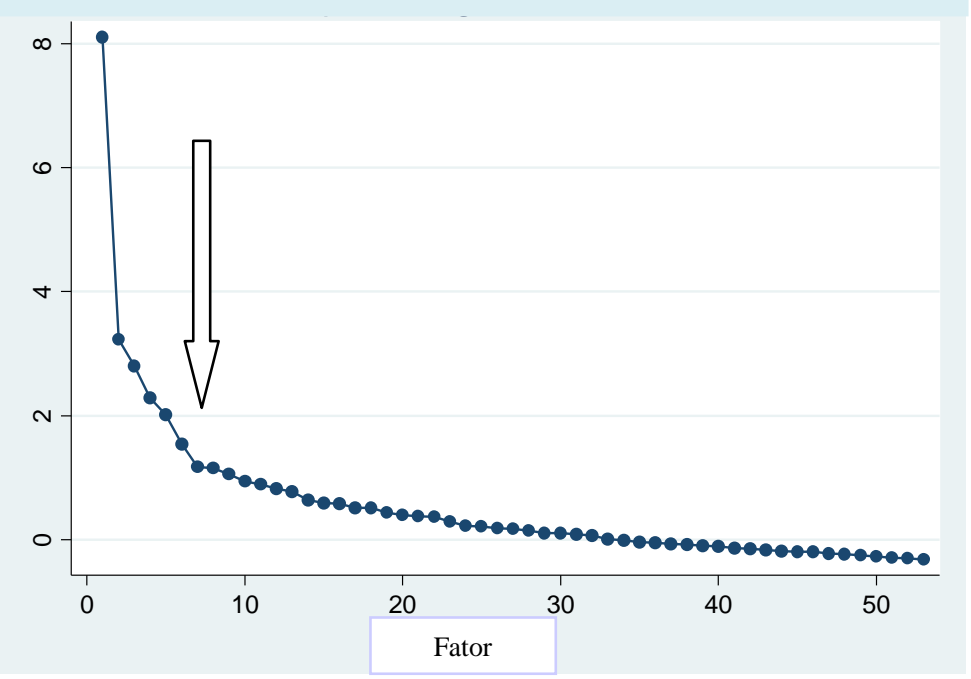

Esses sete fatores explicaram $71,66 \%$ da variância de intercorrelações. Foram eliminadas quinze variáveis do questionário de EdV ao analisar os valores de carga maiores que 0,4 e menores que $-0,4$. A tabela 6 mostra os valores de carga (achurados) dos itens remanescentes dentro dos sete fatores. 
Tabela 6 - Valores de carga dos fatores remanescentes do questionário AIOV de estilo de vida, Região Sudoeste, São Paulo, SP - 2011

\begin{tabular}{|c|c|c|c|c|c|c|c|}
\hline \multirow[b]{2}{*}{ Variável } & \multicolumn{7}{|c|}{ VALORES DE CARGA } \\
\hline & Fator 1 & Fator 2 & Fator 3 & Fator 4 & Fator 5 & Fator 6 & Fator 7 \\
\hline 1 & 0,05 & 0,20 & $-0,14$ & $-0,05$ & 0,04 & 0,49 & 0,08 \\
\hline 2 & 0,12 & 0,18 & 0,04 & 0,25 & $-0,07$ & $-0,03$ & 0,49 \\
\hline 3 & $-0,01$ & $-0,10$ & $-0,02$ & $-0,58$ & 0,02 & $-0,02$ & $-0,13$ \\
\hline 4 & $-0,17$ & $-0,02$ & 0,06 & $-0,09$ & 0,73 & 0,04 & 0,01 \\
\hline 6 & 0,15 & 0,50 & $-0,14$ & 0,13 & $-0,01$ & 0,10 & 0,01 \\
\hline 9 & 0,08 & 0,08 & $-0,05$ & $-0,01$ & 0,07 & 0,60 & 0,07 \\
\hline 11 & 0,14 & $-0,01$ & $-0,02$ & 0,57 & $-0,07$ & 0,03 & 0,20 \\
\hline 12 & 0,04 & 0,06 & $-0,07$ & $-0,07$ & 0,69 & 0,05 & $-0,01$ \\
\hline 15 & 0,08 & 0,17 & $-0,05$ & 0,02 & 0,15 & 0,45 & 0,04 \\
\hline 18 & $-0,11$ & $-0,03$ & 0,08 & 0,10 & 0,05 & $-0,07$ & 0,64 \\
\hline 19 & $-0,03$ & 0,25 & 0,07 & $-0,61$ & 0,00 & 0,07 & $-0,20$ \\
\hline 20 & 0,00 & 0,03 & $-0,08$ & 0,10 & 0,65 & 0,02 & 0,03 \\
\hline 21 & $-0,06$ & 0,73 & $-0,04$ & $-0,06$ & 0,03 & 0,07 & 0,04 \\
\hline 22 & 0,02 & 0,70 & $-0,01$ & 0,03 & 0,07 & 0,15 & $-0,03$ \\
\hline 24 & $-0,01$ & 0,23 & 0,13 & $-0,06$ & $-0,03$ & 0,62 & $-0,13$ \\
\hline 25 & $-0,20$ & 0,00 & 0,11 & 0,15 & 0,01 & 0,12 & 0,51 \\
\hline 26 & 0,15 & $-0,48$ & $-0,04$ & 0,11 & 0,14 & 0,00 & $-0,02$ \\
\hline 27 & 0,08 & 0,56 & $-0,08$ & 0,17 & 0,07 & 0,18 & $-0,09$ \\
\hline 30 & 0,06 & $-0,12$ & 0,65 & $-0,06$ & $-0,04$ & $-0,06$ & 0,14 \\
\hline 32 & 0,42 & 0,01 & 0,22 & 0,17 & 0,16 & 0,04 & 0,01 \\
\hline 33 & 0,40 & 0,14 & 0,12 & 0,10 & 0,16 & $-0,22$ & $-0,11$ \\
\hline 34 & 0,20 & 0,21 & 0,14 & 0,53 & 0,13 & 0,00 & 0,13 \\
\hline 35 & 0,14 & $-0,06$ & 0,58 & 0,06 & $-0,02$ & 0,02 & $-0,01$ \\
\hline 37 & 0,32 & 0,41 & 0,14 & $-0,06$ & 0,20 & $-0,29$ & 0,02 \\
\hline 39 & 0,58 & 0,08 & 0,02 & 0,01 & 0,04 & 0,21 & 0,02 \\
\hline 40 & 0,17 & 0,45 & 0,26 & 0,03 & 0,19 & $-0,23$ & $-0,07$ \\
\hline 41 & 0,60 & 0,19 & 0,04 & 0,02 & 0,14 & $-0,08$ & $-0,26$ \\
\hline 42 & 0,42 & $-0,17$ & $-0,30$ & 0,13 & 0,18 & 0,33 & $-0,01$ \\
\hline 43 & 0,62 & $-0,14$ & 0,13 & 0,07 & $-0,09$ & 0,21 & 0,03 \\
\hline 44 & 0,21 & $-0,16$ & 0,10 & $-0,44$ & 0,21 & 0,19 & 0,27 \\
\hline 45 & 0,34 & 0,00 & 0,47 & 0,07 & $-0,11$ & 0,11 & $-0,05$ \\
\hline 47 & 0,71 & $-0,10$ & 0,15 & $-0,05$ & $-0,13$ & 0,21 & 0,05 \\
\hline 48 & 0,63 & 0,04 & 0,10 & $-0,20$ & $-0,04$ & $-0,09$ & 0,10 \\
\hline 49 & 0,57 & 0,10 & 0,04 & 0,17 & $-0,01$ & $-0,08$ & 0,06 \\
\hline 50 & 0,65 & 0,11 & $-0,02$ & 0,03 & 0,02 & $-0,19$ & 0,03 \\
\hline 51 & 0,57 & 0,24 & $-0,01$ & 0,09 & $-0,08$ & $-0,25$ & $-0,01$ \\
\hline 52 & 0,60 & 0,02 & 0,11 & $-0,02$ & $-0,01$ & 0,08 & $-0,06$ \\
\hline 53 & 0,36 & $-0,03$ & $-0,05$ & $-0,51$ & 0,13 & 0,00 & 0,35 \\
\hline
\end{tabular}

Os fatores um, dois, três, quatro, cinco, seis e sete receberam os seguintes nomes, respectivamente, de acordo com as características dos itens de maior valor de carga: Integrado; Vida familiar; Centrado no conforto pessoal; Caseiro; Consciente socialmente; Econômico e Moderno. 
Para efeito de validação de conteúdo, o item "É bom trabalhar em campanha política" de número vinte e seis foi eliminado do questionário final por ter sido designado a um fator com contexto diferente do que é proposto pelo item. Os nomes dos fatores e itens com as opções de resposta do questionário final estão no quadro 1. 
Quadro 1 - Nomes dos fatores, dos itens e opções de resposta do questionário de Estilo de Vida AIOV.

\begin{tabular}{|c|c|c|c|c|c|c|}
\hline Fatores & \multirow{2}{*}{$\begin{array}{l}\text { Itens } \\
\text { 32. Trabalho/emprego. }\end{array}$} & \multicolumn{5}{|c|}{ Opções de resposta } \\
\hline \multirow{12}{*}{ Integrado } & & \multirow{12}{*}{$\begin{array}{c}\text { Nada } \\
\text { importante }\end{array}$} & \multirow{12}{*}{$\begin{array}{c}\text { Pouco } \\
\text { importante }\end{array}$} & \multirow{12}{*}{ Importante } & \multirow{12}{*}{$\begin{array}{l}\text { Muito } \\
\text { importante }\end{array}$} & \multirow{12}{*}{$\begin{array}{l}\text { Totalmente } \\
\text { importante }\end{array}$} \\
\hline & 33. Ter estudo. & & & & & \\
\hline & 39. Realização dos sonhos. & & & & & \\
\hline & 41. Relacionamento com os filhos. & & & & & \\
\hline & 42. Ser reconhecido na comunidade. & & & & & \\
\hline & 43. Ser reconhecido no trabalho. & & & & & \\
\hline & 47. Uma vida de sonhos realizados. & & & & & \\
\hline & 48. Ter o respeito das pessoas. & & & & & \\
\hline & 49. Aproveitar a vida. & & & & & \\
\hline & 50. Segurança para viver. & & & & & \\
\hline & 51. Ter respeito a mim mesmo. & & & & & \\
\hline & 52. Sentimento de ter alcançado o que desejei. & & & & & \\
\hline & $\begin{array}{l}\text { 6. Acho importante as crianças arrumarem os } \\
\text { brinquedos. }\end{array}$ & & & & & \\
\hline & $\begin{array}{l}\text { 21. Arrumo a minha casa para o conforto da } \\
\text { família. }\end{array}$ & $\begin{array}{l}\text { Discordo } \\
\text { totalmente }\end{array}$ & Discordo & $\begin{array}{l}\text { concordo } \\
\text { e nem }\end{array}$ & Concordo & $\begin{array}{l}\text { Concordo } \\
\text { totalmente }\end{array}$ \\
\hline Vida Familiar & 22. Gosto quando minha casa está limpa. & & & discordo & & \\
\hline & 27. Ensino bons hábitos aos meus filhos. & & & & & \\
\hline & 37. Relacionamento familiar. & Nada & Pouco & Imnortante & Muito & Totalmente \\
\hline & 40. Relacionamento com o companheiro. & importante & importante & mingortante & importante & importante \\
\hline & 30. Ter dinheiro. & & & & & \\
\hline $\begin{array}{l}\text { Centrado no } \\
\text { conforto pessoal }\end{array}$ & 35. Conforto material. & $\begin{array}{l}\text { Nada } \\
\text { importante }\end{array}$ & $\begin{array}{l}\text { Pouco } \\
\text { importante }\end{array}$ & Importante & $\begin{array}{l}\text { Muito } \\
\text { importante }\end{array}$ & $\begin{array}{l}\text { Totalmente } \\
\text { importante }\end{array}$ \\
\hline & 45. Uma boa condição de vida. & & & & & \\
\hline & $\begin{array}{l}\text { 3. Prefiro ficar em casa em vez de ir a uma } \\
\text { festa (sentido inverso). }\end{array}$ & & & & & \\
\hline & $\begin{array}{l}\text { 11. Gosto de festas onde há música e } \\
\text { conversa. }\end{array}$ & $\begin{array}{l}\text { Discordo } \\
\text { totalmente }\end{array}$ & Discordo & $\begin{array}{l}\text { concordo } \\
\text { e nem }\end{array}$ & Concordo & $\begin{array}{l}\text { Concordo } \\
\text { totalmente }\end{array}$ \\
\hline Caseiro & $\begin{array}{l}\text { 19. Sou uma pessoa caseira (sentido } \\
\text { inverso). }\end{array}$ & & & discordo & & \\
\hline Caseliro & 34. Divertimento. & $\begin{array}{c}\text { Nada } \\
\text { importante }\end{array}$ & \begin{tabular}{|c|} 
Pouco \\
importante
\end{tabular} & Importante & $\begin{array}{c}\text { Muito } \\
\text { importante }\end{array}$ & $\begin{array}{l}\text { Totalmente } \\
\text { importante }\end{array}$ \\
\hline & $\begin{array}{l}\text { 44. Viver de acordo com as regras religiosas } \\
\text { (sentido inverso) }\end{array}$ & $\begin{array}{l}\text { Nada } \\
\text { importante }\end{array}$ & \begin{tabular}{|l|} 
Pouco \\
importante
\end{tabular} & Importante & $\begin{array}{c}\text { Muito } \\
\text { importante }\end{array}$ & $\begin{array}{l}\text { Totalmente } \\
\text { importante }\end{array}$ \\
\hline & 53. Chegar a Deus & $\begin{array}{c}\text { Nada } \\
\text { importante }\end{array}$ & $\begin{array}{c}\text { Pouco } \\
\text { importante }\end{array}$ & Importante & $\begin{array}{c}\text { Muito } \\
\text { importante }\end{array}$ & $\begin{array}{l}\text { Totalmente } \\
\text { importante }\end{array}$ \\
\hline & $\begin{array}{l}\text { 4. Participo de um grupo de pessoas que } \\
\text { ajuda a comunidade. }\end{array}$ & & & $\begin{array}{c}\text { Não } \\
\text { concordo }\end{array}$ & & \\
\hline socialmente & 12. Faço trabalho voluntário. & totalmente & Discordo & e nem & Concordo & totalmente \\
\hline & 20. É gostoso trabalhar para a comunidade. & & & discordo & & \\
\hline & 1. Procuro por bons preços. & & & & & \\
\hline & 15. Me informo antes de comprar. & & & & & \\
\hline Econômico & $\begin{array}{l}\text { 9. Eu verifico preços mesmo para itens } \\
\text { pequenos. }\end{array}$ & $\begin{array}{l}\text { Discordo } \\
\text { totalmente }\end{array}$ & Discordo & $\begin{array}{l}\text { concordo } \\
\text { e nem }\end{array}$ & Concordo & $\begin{array}{l}\text { Concordo } \\
\text { totalmente }\end{array}$ \\
\hline & $\begin{array}{l}\text { 24. Uma pessoa economiza um bom } \\
\text { dinheiro procurando bons preços. }\end{array}$ & & & discordo & & \\
\hline & 2. Costumo ter uma ou mais roupas da moda. & & & Não & & \\
\hline Moderno & 18. Vestir roupas da moda é importante. & $\begin{array}{l}\text { Discordo } \\
\text { totalmente }\end{array}$ & Discordo & $\begin{array}{l}\text { concordo } \\
\text { e nem }\end{array}$ & Concordo & $\begin{array}{l}\text { Concordo } \\
\text { totalmente }\end{array}$ \\
\hline & 25. Experimento os cortes de cabelo da moda. & & & discordo & & \\
\hline
\end{tabular}




\section{DISCUSSÃo}

Descrever estilo de vida é uma difícil tarefa devido à dimensionalidade de sua composição, além da dificuldade inerente ao realizar uma medição de um aspecto subjetivo por método objetivo. Na área da saúde, os estudos existentes utilizam instrumentos de medição de comportamentos saudáveis de EdV. Na mesma área, não foram encontrados estudos que avaliam o EdV materno e seu impacto sobre a saúde do pré-escolar sob visão das atividades, interesses, opiniões e valores inerentes ao comportamento das próprias mães. Já na área mercadológica, foi encontrado apenas um trabalho fazendo relações com segmentações de estilo de vida relacionado aos comportamentos alimentares de adultos ${ }^{47}$.

Neste estudo, elaboramos e validamos um instrumento capaz de medir o estilo de vida de mães de pré-escolares. Esta pesquisa é relevante, pois descreve o EdV materno sob outra dimensão e que poderá compreender como as atividades, interesses, opiniões e valores das mães influenciam os aspectos nutricionais do préescolar.

O estudo foi realizado com mulheres de todas as classes econômicas com o intuito de o questionário poder ser respondido por pessoas com poucos anos de estudo. Pode-se dizer que a validação do questionário foi especialmente baseada em respostas dadas por mulheres da classe $\mathrm{C}$, casadas, com nível médio de ensino e mães de crianças estudantes em escolas públicas e moradoras do Morumbi.

Os instrumentos encontrados que talvez pudessem ser aglomerados entre si e formar um mais genérico de EdV foram: Questionário para avaliar valores e estilo de vida; Escala para mensurar a auto-imagem e imagem de produtos e Frases de AIO. Durante o desenvolvimento do instrumento, considerou-se a utilidade dos itens e a 
facilidade de entendimento pela população na escolha dos mesmos. Para efeitos de adequação à cultura brasileira, entendimento dos itens e dificuldade em dar resposta os dois instrumentos - Valores e Estilo de Vida e Escala para mensurar a autoimagem e imagem de produtos - foram eliminados. As frases remanescentes de AIOV permitiram identificar sete domínios de estilo de vida. $O$ instrumento final mostrou ser simples, de fácil compreensão e aplicação, podendo ser utilizado sob a forma de entrevista ou auto-aplicável.

O questionário consistiu de duas seções. A primeira com vinte e nove itens sobre as atividades, interesses e opiniões e a segunda com vinte e quatro itens sobre os valores pessoais das mães. Os itens utilizados na primeira seção foram semelhantes aos utilizados por Kucukemiroglu ${ }^{46}$ em 1997.

No estudo piloto, o valor do alfa de Cronbach obtido esteve dentro da faixa aceitável, mostrando que o questionário media o que estava pretendendo medir. Entretanto, a maioria dos itens teve um coeficiente de correlação pairwise menor que 0,5 . Isso pode ser explicado pelo fato de terem sido escritos de forma a possibilitar dificuldade em dar resposta como presença de advérbios e palavras negativas, além de serem extensos, ambíguos e passarem mais que uma ideia Anexo C. Adicionalmente, os vieses intrínsecos ao fato de responder a um questionário contribuíram para realizar mudança dos itens no estudo piloto. Os itens passaram um sentido diferente do que o proposto inicialmente. Além disso, foi necessário que as mães se lembrassem como era o comportamento que tinham frente ao significado do item. Mesmo tendo compreendido o item e recordado as ações, foi necessário que elas fizessem uma estimativa ou inferência da freqüência do comportamento. Mesmo tendo passado por todos os problemas citados, as mães ainda puderam encontrar dificuldade em diferenciar os tipos de resposta ${ }^{60}$. Algumas 
não conseguiram diferenciar a intensidade entre as duas respostas 'muito importante' e 'totalmente importante' do questionário de valores pessoais. Foi necessário realizar uma explicação verbal da diferença durante a entrevista realizada pelo pesquisador de campo e a mãe.

Na pesquisa final, a consistência interna avaliada através do alfa de Cronbach foi de 0,83 , valor inferior ao obtido por Kucukemiroglu ${ }^{46}$ (1997) que foi de 0,92. Em tal estudo, o questionário continha 56 itens de AIO e um tamanho amostral de quinhentos e trinta e dois respondentes. Para evitar que este trabalho tivesse as limitações pertinentes de um único teste, a aplicação do questionário em reteste permitiu obter um coeficiente de correlação pairwise maior que 0,5 , valor recomendado para estudos de medição de aspectos subjetivos ${ }^{60}$.

De acordo com Streiner e Norman ${ }^{60}$ (2008), a melhor faixa de valores que representa o alfa situa-se entre 0,7 e 0,9. Porém, quando o valor é menor que 0,7 tem-se um questionário que provavelmente aborda construto diferente do que aquele a que se quer medir e maior que 0,9 há uma concordância extremamente alta proveniente de uma redundância entre os itens ${ }^{55,65}$.

A reprodutibilidade teste-reteste permitiu mostrar a estabilidade na vida das respondentes, uma vez que as respostas dadas às questões foram iguais ou semelhantes na entrevista seguinte. É importante considerar o tempo transcorrido entre as duas avaliações. O tempo médio em que aconteceu o reteste foi de 7,5 dias, com variação de 3,7 a 11,3 dias. Recomenda-se que o teste-reteste aconteça entre dois a quatorze dias ${ }^{55,65}$, a fim de se reduzir a possibilidade de grandes mudanças. Caso o reteste aconteça num período menor que dois dias, a entrevistada poderá dar a mesma resposta dada na primeira entrevista, o que aumentará o coeficiente de correlação, fazendo com que o instrumento tenha uma 
falsa confiabilidade. Caso aconteça num período maior que quatorze dias, a resposta dada no reteste estará sujeita às mudanças ocorridas na vida da entrevistada, podendo também levar uma falsa confiabilidade do instrumento e a uma classificação errônea do EdV da mãe.

Para averiguar a existência e características de dimensões de EdV, as frases do questionário AIOV submetidas à análise fatorial identificaram cinquenta e três fatores ou EdV. Sete deles explicaram mais de dois terços da variância de intercorrelações. Os fatores remanescentes foram então submetidos à rotação varimax com a finalidade de corrigir alguns aspectos como os que serão descritos a seguir: na análise fatorial, o primeiro fator tem a característica de ser geral e possuir muitos itens. Isso é resultante do fato de todas as medidas terem sido feitas nas mesmas pessoas, favorecendo a correlação entre os itens. O segundo aspecto é quanto à bipolaridade dos itens, tornando-se difícil saber a qual fator pertence. O terceiro é a complexidade fatorial dos itens, ou seja, sem a rotação varimax o item possui valor de carga parecido em dois fatores. E, por último, o item pode possuir um valor médio de carga, sendo preferível que o valor esteja nos extremos.

Após a realização da rotação varimax para correção dos aspectos citados, foram avaliados os fatores de carga de cada item dentro de cada fator. Cada fator ficou constituído por itens que possuíram valor de carga maior ou igual a 0,40 ou menor ou igual a $-0,40$, ponto de corte definido pelo tamanho amostral.

Os fatores foram nomeados com base nos itens de maior valor de carga e pela junção de sentido de todos os itens que os compunham. O fator um foi nomeado como 'Integrado' e é constituído pelos itens de valor pessoal: 'trabalho/emprego'; 'ter estudo'; 'realização dos sonhos'; 'relacionamento com os filhos'; 'ser reconhecido na comunidade'; 'ser reconhecido no trabalho'; 'uma vida de sonhos realizados'; 'ter o 
respeito das pessoas'; 'aproveitar a vida'; 'segurança para viver'; 'ter respeito a mim mesmo'; 'sentimento de ter alcançado o que desejei'.

O fator dois recebeu o nome de 'Vida familiar' e era composto pelos itens de valores e AIO: 'acho importante as crianças arrumarem os brinquedos'; 'arrumo a minha casa para o conforto da família'; 'gosto quando minha casa está limpa'; 'ensino bons hábitos aos meus filhos'; 'relacionamento familiar e relacionamento com o companheiro'.

O fator três recebeu o nome de 'Centrado no conforto pessoal'. Os itens 'ter dinheiro'; 'conforto material' e 'uma boa condição de vida' compuseram tal fator.

O fator quatro foi nomeado como 'Caseiro' e era formado pelos itens 'prefiro ficar em casa em vez de ir a uma festa' (com sentido inverso); 'gosto de festas onde há música e conversa'; 'sou uma pessoa caseira' (com sentido inverso); 'divertimento'; 'viver de acordo com as regras religiosas' (com sentido inverso) e 'chegar a Deus' (com sentido inverso).

'Participo de um grupo de pessoas que ajuda a comunidade'; 'faço trabalho voluntário' e 'é gostoso trabalhar para a comunidade' são itens que fazem parte do quinto fator nomeado como 'Consciente socialmente'.

O sexto fator chamado de 'Econômico' contém os itens 'procuro por bons preços'; 'me informo antes de comprar'; 'eu verifico preços mesmo para itens pequenos'; 'uma pessoa economiza um bom dinheiro procurando bons preços'.

O sétimo e último fator recebeu o nome de 'Moderno' e é formado pelos itens 'costumo ter uma ou mais roupas da moda'; 'vestir roupas da moda é importante' e 'experimento os cortes de cabelo da moda'.

Esses fatores ou domínios são características do estilo de vida que cada mãe apresenta, ou seja, são aspectos do que fazem, do que se interessam, opinam ou 
têm como valores para si. Isso difere do conceito de estilo de vida utilizado por pesquisadores da área de saúde no sentido de que sai do foco de comportamentos de risco e identifica as atividades, os interesses, as opiniões e os valores que estão por traz dos comportamentos de risco e como isso influencia a saúde da criança.

Vale ressaltar que esses sete fatores não são excludentes entre si, mas devem ser utilizados para comparar mães com mais ou menos pontuação em cada fator. $\mathrm{O}$ instrumento possibilita medir de forma comparativa o grau de exposição aos fatores encontrados. Nesse sentido, estudos que venham a utilizá-lo poderão classificar os sujeitos estudados em tercis de baixa, média e alta pontuação em cada um dos fatores. A identificação das sete dimensões de EdV permitirá entender, por exemplo, como é o estado nutricional, alimentação, morbidade e atividade física de uma criança filha de mãe pertencente à dimensão moderna ou econômica. Ou seja, será que o fato de uma mãe possuir a característica de poupar dinheiro fará com que 0 filho tenha uma alimentação pior, ou melhor? Um estudo transversal já está em curso para testar essas hipóteses de associação.

Devido à falta de instrumento de AIOV de referência, torna-se difícil realizar comparações do questionário aqui validado. Isso não permite concluir que as frases de AIOV utilizadas nesta pesquisa descrevem completamente as atividades, interesses, opiniões e valores das pessoas que as fazem ter determinadas características.

Como a pesquisa foi realizada na Região Sudoeste do Município de São Paulo, não se pode dizer que os EdV identificados sejam encontrados em universo maior do que naquele estudado por esta pesquisa, embora a validação do questionário possa ser admitida para o ambiente nacional. É importante ressaltar que o 
questionário na forma como foi aplicado e validado destina-se a mulheres adultas jovens sem problemas aparentes de saúde mental.

A técnica estatística utilizada, análise fatorial, pode sintetizar de forma excessiva os itens do questionário, fazendo com que o significado e conteúdo de cada item eliminado seja perdido.

O questionário 'Estilo de vida AIOV' é uma ferramenta para auxiliar os pesquisadores a compreender o que está por trás dos comportamentos de risco materno relacionados à saúde de pré-escolares. 


\section{CONCLUSÕES}

O questionário delineado é o primeiro instrumento capaz de descrever sete tipos de Estilos de Vida, segundo um paradigma sociológico, de mães de crianças em idade pré-escolar. Ele possui validade de conteúdo e boa confiabilidade como pode ser observado através do alfa de Cronbach e dos coeficientes de correlação pairwise. Por não ter sido comparado com um critério externo, não possui validade de critério. Dada a dificuldade de compreensão para pessoas menos estudadas, para alguns esse é um questionário de auto-preenchimento e para outros deve ser aplicado por meio de entrevista. 


\section{ANEXOS}

\section{Anexo A - Critério de Classificação Econômica Brasil}

Para aparelhos domésticos em geral devemos considerar os seguintes casos: Bem alugado em caráter permanente; Bem emprestado de outro domicílio há mais de 6 meses; Bem quebrado há menos de 6 meses.

Não considerar os seguintes casos: Bem emprestado para outro domicílio há mais de 6 meses; Bem quebrado há mais de 6 meses; Bem alugado em caráter eventual; Bem de propriedade de empregados ou pensionistas.

Posse de itens: Marcar com um "x" sobre o número correspondente ao número de itens de cada equipamento que possui em casa.

\begin{tabular}{|c|c|c|c|c|c|}
\hline & \multicolumn{5}{|c|}{ Quantidade de itens } \\
\hline & 0 & 1 & 2 & 3 & $\begin{array}{c}4 \text { ou } \\
+\end{array}$ \\
\hline $\begin{array}{l}\text { Televisão em cores: próprio ou emprestado há mais de } \\
6 \text { meses ou quebrado há menos de } 6 \text { meses. De uso de } \\
\text { empregados, considerar se for adquirido pela família } \\
\text { empregadora. }\end{array}$ & 0 & 1 & 2 & 3 & 4 \\
\hline $\begin{array}{l}\text { Rádio: qualquer tipo que seja capaz de sintonizar } \\
\text { emissoras. Não considerar rádio de automóvel. }\end{array}$ & 0 & 1 & 2 & 3 & 4 \\
\hline $\begin{array}{l}\text { Banheiro: deve conter vaso sanitário. Não considerar } \\
\text { banheiro coletivo. }\end{array}$ & 0 & 4 & 5 & 6 & 7 \\
\hline $\begin{array}{l}\text { Automóvel: não considerar veículos para uso } \\
\text { profissional ou para fretes (vans, táxis, pick up). Não } \\
\text { considerar de uso misto. }\end{array}$ & 0 & 4 & 7 & 9 & 9 \\
\hline $\begin{array}{l}\text { Empregada mensalista: Não se refere a regime de } \\
\text { salário, mas se trabalha pelo menos } 5 \text { dias por semana, } \\
\text { dormir ou não no emprego. Considerar babás, motoristas, } \\
\text { copeiras, cozinheiras, arrumadeiras. }\end{array}$ & 0 & 3 & 4 & 4 & 4 \\
\hline $\begin{array}{l}\text { Máquina de lavar: automáticas ou semi-automáticas. } \\
\text { Não considerar tanquinho. }\end{array}$ & 0 & 2 & 2 & 2 & 2 \\
\hline Videocassete e/ou DVD. & 0 & 2 & 2 & 2 & 2 \\
\hline Geladeira & 0 & 4 & 4 & 4 & 4 \\
\hline $\begin{array}{l}\text { Freezer (aparelho independente ou parte da geladeira } \\
\text { duplex) }\end{array}$ & 0 & 2 & 2 & 2 & 2 \\
\hline
\end{tabular}


Grau de instrução do chefe da família: Marcar com um "x" sobre uma única resposta como sendo seu grau de instrução.
a) Analfabeto / Primário incompleto / Até 3a Série Fundamental (0).
b) Primário completo / Ginasial incompleto / Até 4⿳a Série Fundamental (1).
c) Ginasial Completo / Colegial incompleto / Fundamental completo (2).
d) Colegial completo / Superior incompleto / Médio completo (4).
e) Superior completo (8).

Cortes do Critério Brasil:

Classe A: 35 a 46 pontos

Classe B: 23 a 34 pontos

Classe C: 14 a 22 pontos

Classe D: 8 a 13 pontos

Classe E: 0 a 7 pontos

FONTE: ABEP ${ }^{71}, 2007$. 


\section{Anexo B - Instrumentos para elaboração do questionário de Estilo de Vida}

AIOV

\section{Questionário para avaliar valores e estilo de vida.}

Responda às seguintes afirmações, usando as seguintes categorias: Discordo totalmente, Discordo em termos, Concordo em termos, Concordo totalmente.

1. Frequentemente me interesso por teorias.

2. Não aprecio pessoas e coisas escandalosas.

3. Gosto de muita variedade em minha vida.

4. Gosto de fazer coisas que possa usar todos os dias.

5. Sigo as últimas tendências da moda.

6. Conforme diz a Bíblia, o mundo foi realmente criado em seis dias.

7. Gosto de ser responsável por um grupo.

8. Gosto de aprender sobre arte, cultura e história.

9. Frequentemente adoro coisas estimulantes.

10. Interesso-me realmente por apenas algumas coisas.

11. Prefiro fazer algo a comprá-lo.

12. Visto-me mais na moda que a maioria das pessoas.

13. O governo federal deveria encorajar a prática da oração nas escolas públicas.

14. Tenho mais habilidade que a maioria das pessoas. 
15. Considero-me um intelectual.

16. Devo admitir que gosto de me exibir.

17. Gosto de experimentar coisas novas.

18. Sou muito interessado em saber como coisas mecânicas - por exemplo, como os motores funcionam.

19. Gosto de me vestir na última moda.

20. Há muito sexo na TV hoje em dia.

21. Gosto de liderar.

22. Eu gostaria de passar um ano ou mais em um país estrangeiro.

23. Gosto de muita agitação em minha vida.

24. Devo admitir que meus interesses são um pouco restritos e limitados.

25. Gosto de fazer coisas de madeira, metal ou outros materiais.

26. Quero ser considerado um pessoa que anda na moda.

27. A vida de uma mulher só está completa se ela pode propiciar um lar feliz para sua família.

28. Gosto do desafio de fazer algo que nunca fiz antes.

29. Gosto de aprender sobre coisas, mesmo que elas nunca me sejam úteis.

30. Gosto de fazer coisas com as minhas mãos.

31. Estou sempre buscando emoções.

32. Gosto de fazer coisas novas e diferentes.

33. Gosto de examinar lojas de máquinas e carros.

34. Eu gostaria de entender mais sobre como funciona o universo.

35. Gosto que minha vida seja sempre a mesma.

FONTE: Sheth ${ }^{43}, 2001$. 


\section{Escala para mensurar a auto imagem e imagem de produtos}

Instrução: Classifique-se como você se vê em relação aos seguintes pares de palavras descritivas, fazendo um círculo em volta de um número de cada fileira que esteja mais próximo da descrição de sua personalidade.

$\begin{array}{llllllllr}\text { Rude } & 1 & 2 & 3 & 4 & 5 & 6 & 7 & \text { Delicado } \\ \text { Agitado } & 1 & 2 & 3 & 4 & 5 & 6 & 7 & \text { Calmo } \\ \text { Tenso } & 1 & 2 & 3 & 4 & 5 & 6 & 7 & \text { Relaxado } \\ \text { Dominador } & 1 & 2 & 3 & 4 & 5 & 6 & 7 & \text { Submisso } \\ \text { Econômico } & 1 & 2 & 3 & 4 & 5 & 6 & 7 & \text { Perdulário } \\ \text { Agradável } & 1 & 2 & 3 & 4 & 5 & 6 & 7 & \text { Desagradável } \\ \text { Contemporâneo } & 1 & 2 & 3 & 4 & 5 & 6 & 7 & \text { Anacrônico } \\ \text { Organizado } & 1 & 2 & 3 & 4 & 5 & 6 & 7 & \text { Desorganizado } \\ \text { Racional } & 1 & 2 & 3 & 4 & 5 & 6 & 7 & \text { Emocional } \\ \text { Jovem } & 1 & 2 & 3 & 4 & 5 & 6 & 7 & \text { Maduro } \\ \text { Formal } & 1 & 2 & 3 & 4 & 5 & 6 & 7 & \text { Informal } \\ \text { Ortodoxo } & 1 & 2 & 3 & 4 & 5 & 6 & 7 & \text { Liberal } \\ \text { Complexo } & 1 & 2 & 3 & 4 & 5 & 6 & 7 & \text { Simples } \\ \text { Sem cor } & 1 & 2 & 3 & 4 & 5 & 6 & 7 & \text { Colorido } \\ \text { Modesto } & 1 & 2 & 3 & 4 & 5 & 6 & 7 & \text { Vaidoso }\end{array}$

FONTE: Engel et al. ${ }^{42}, 2000$. 


\section{Frases de AIO}

Algumas amostras de atividades, interesses e opiniões que definem estilos de vida.

Responda às seguintes afirmações, usando as seguintes categorias: Discordo totalmente, Discordo em termos, Concordo em termos, Concordo totalmente.

\section{Consciente de preços}

1. Procuro muito por ofertas especiais.

2. Eu me vejo verificando os preços na quitanda mesmo para itens pequenos.

3. Geralmente assisto a propagandas na busca de anúncios de liquidações.

4. Uma pessoa pode economizar um belo dinheiro procurando pechinchas.

\section{Consciente da moda}

5. Geralmente tenho um ou mais trajes que estão na última moda.

6. Quando preciso escolher entre duas coisas, geralmente visto o que está na moda, não o que é confortável.

7. Uma importante parte da minha vida e atividades é me vestir bem.

8. Geralmente experimento os mais modernos cortes de cabelo quando eles são lançados.

\section{$\underline{\text { Caseiro }}$}

9. Prefiro passar uma noite tranquila em casa a ir a uma festa.

10. Gosto de festas onde há muita música e conversa (pontuação inversa).

11. Prefiro ir a um evento esportivo a dançar.

12. Sou caseiro. 


\section{Voltado para comunidade}

13. Sou um membro ativo de mais de uma organização de serviços.

14. Faço trabalho voluntário para um hospital ou alguma organização de serviços com bastante frequência.

15. Gosto de trabalhar em projetos comunitários.

16. Trabalhei pessoalmente em uma campanha política ou para um candidato ou uma causa.

Orientado para os filhos

17. Quando meus filhos ficam doentes, deixo de fazer quase tudo para cuidar deles.

18. Meus filhos são a coisa mais importante da minha vida.

19. Tento arrumar minha casa para a conveniência de meus filhos.

20. Gasto muito tempo e esforço tentando ensinar bons hábitos aos meus filhos.

Dona-de-casa compulsiva

21. Não gosto de ver os brinquedos das crianças espalhados pela casa.

22. Geralmente mantenho minha casa muito arrumada e limpa.

23. Sinto-me mal quando minha casa não está completamente limpa.

24. Nossos dias parecem seguir uma rotina definida com refeições na hora certa, por exemplo.

\section{$\underline{\text { Autoconfiante }}$}

25. Acho que tenho mais autoconfiança que a maioria das pessoas.

26. Sou mais independente que a maioria das pessoas.

27. Acho que tenho muita habilidade pessoal.

Acha que é líder de opinião

28. Meus amigos e vizinhos frequentemente me procuram para que eu os aconselhe. 
29. Algumas vezes influencio o que meus amigos compram.

30. As pessoas me procuram mais do que as procuro para informações sobre marcas.

\section{Busca informações}

31. Frequentemente busco o aconselhamento de meus amigos sobre que marca comprar.

32. Despendo um tempo considerável conversando com meus amigos sobre marcas e produtos.

\section{Não gosta de serviços domésticos}

33. Devo admitir que realmente não gosto de tarefas domésticas.

34. Acho limpar a casa uma tarefa desagradável.

35. Aprecio a maioria das formas de tarefas domésticas (pontuação contrária).

36. Minha ideia de serviço doméstico é "muito de vez em quando".

\section{Gosta de costurar}

37. Gosto de costurar e o faço com frequência.

38. Quase sempre faço minhas roupas e as de meus filhos.

39. Pode-se economizar um bom dinheiro fazendo as próprias roupas.

40. Gostaria de saber costurar como um profissional.

Consumidor de comida enlatada

41. Dependo de comidas enlatadas pelo menos em uma refeição por dia.

42. Eu não sobreviveria sem comidas enlatadas.

43. Comida enlatada tem um sabor esquisito (pontuação contrária).

\section{Faz dietas}

44. Durante o verão bebo refrigerantes de baixa caloria várias vezes por semana.

45. Já usei Metrecal e outras comidas dietéticas pelo menos em uma refeição diária. 


\section{Otimista em termos financeiros}

46. Provavelmente terei mais dinheiro para gastar no próximo ano do que tenho agora.

47. Daqui a cinco anos a renda familiar será provavelmente bem mais alta do que é agora.

FONTE: WELLS e TIGERT ${ }^{35}$ (1971). 


\section{Anexo C - Segunda versão do questionário de Estilo de Vida AIOV}

Responda às seguintes afirmações usando as seguintes categorias: Discordo totalmente, discordo, não concordo e nem discordo, concordo ou concordo totalmente.

1. Procuro sempre por ofertas especiais.

2. Geralmente tenho uma ou mais roupas que estão na última moda.

3. Prefiro passar uma noite tranqüila em casa em vez de ir a uma festa.

4. Sou um membro ativo de uma organização que presta serviços para comunidade.

5. Quando meus filhos ficam doentes, deixo de fazer quase tudo para cuidar deles.

6. Gosto de ver as crianças arrumarem os brinquedos depois de usarem.

7. Meus amigos e vizinhos muitas vezes me procuram para que eu os aconselhe.

8. Provavelmente terei mais dinheiro para gastar no próximo ano do que tenho agora.

9. Eu verifico preços mesmo para itens pequenos.

10. Quando preciso escolher entre duas coisas, geralmente visto o que está na moda, mesmo que seja um pouco desconfortável.

11. Gosto de festas onde há muita música e muita conversa.

12. Faço trabalho voluntário com frequência.

13. Meus filhos são a coisa mais importante de minha vida.

14. Geralmente mantenho minha casa muito limpa e arrumada.

15. Sempre procuro me informar com outras pessoas antes de comprar. 
16. Daqui a cinco anos, a renda familiar será provavelmente bem mais alta do que é agora.

17. Geralmente assisto a propagandas para encontrar liquidações.

18. Para mim, é importante estar bem vestido.

19. Sou uma pessoa caseira.

20. Gosto de trabalhar em projetos comunitários.

21. Tento arrumar minha casa para o conforto de meus filhos.

22. Sinto-me mal quando minha casa não está bem limpa.

23. As tarefas domésticas são muito desagradáveis.

24. Uma pessoa pode economizar um bom dinheiro procurando pechinchas.

25. Geralmente experimentos os cortes mais modernos de cabelo.

26. Gosto de trabalhar em campanha política.

27. Gasto muito tempo para ensinar bons hábitos aos meus filhos.

28. Nós temos uma rotina de vida bem definida.

29. Costuro com frequência as roupas da minha família.

30. Nível de renda.

31. Relacionamento pessoal com os amigos.

32. Trabalho/emprego.

33. Formação cultural (estudo).

34. Lazer pessoal (divertimento).

35. Conforto material.

36. Poupança/patrimônio acumulado.

37. Relacionamento familiar.

38. Saúde.

39. Realização pessoal. 
40. Relacionamento com o companheiro (a).

41. Relacionamento com os filhos.

42. Reconhecimento social.

43. Reconhecimento profissional.

44. Viver dentro dos meus princípios religiosos.

45. Uma boa posição social.

46. Relacionamentos afetuosos bons e duradouros.

47. Uma vida de realizações pessoais.

48. Ser respeitado.

49. Desfrutar a vida.

50. Segurança para viver.

51. Cultivar o respeito próprio.

52. Sentimento de ter alcançado aquilo que aspirei.

53. Chegar a Deus. 


\title{
Anexo D - Versão final do questionário de Estilo de Vida AIOV.
}

\author{
Responda às seguintes afirmações usando as seguintes categorias: Discordo \\ totalmente, discordo, não concordo e nem discordo, concordo ou concordo \\ totalmente.
}

\begin{tabular}{|c|c|c|c|c|c|}
\hline 1. Procuro por bons preços. & $\begin{array}{l}\text { Discordo } \\
\text { Totalmente }\end{array}$ & Discordo & $\begin{array}{l}\text { Não concordo e } \\
\text { nem discordo }\end{array}$ & Concordo & $\begin{array}{l}\text { Concordo } \\
\text { totalmente }\end{array}$ \\
\hline 2. Costumo ter uma ou mais roupas da moda. & $\begin{array}{l}\text { Discordo } \\
\text { Totalmente }\end{array}$ & Discordo & $\begin{array}{l}\text { Não concordo e } \\
\text { nem discordo }\end{array}$ & Concordo & $\begin{array}{l}\text { Concordo } \\
\text { totalmente }\end{array}$ \\
\hline 3. Prefiro ficar em casa em vez de ir a uma festa. & $\begin{array}{l}\text { Discordo } \\
\text { Totalmente }\end{array}$ & Discordo & $\begin{array}{l}\text { Não concordo e } \\
\text { nem discordo }\end{array}$ & Concordo & $\begin{array}{l}\text { Concordo } \\
\text { totalmente }\end{array}$ \\
\hline $\begin{array}{l}\text { 4. Participo de um grupo de pessoas que ajuda a } \\
\text { comunidade. }\end{array}$ & $\begin{array}{l}\text { Discordo } \\
\text { Totalmente }\end{array}$ & Discordo & $\begin{array}{l}\text { Não concordo e } \\
\text { nem discordo }\end{array}$ & Concordo & $\begin{array}{l}\text { Concordo } \\
\text { totalmente }\end{array}$ \\
\hline $\begin{array}{l}\text { 5. Quando meus filhos ficam doentes, deixo de fazer } \\
\text { algumas coisas para cuidar deles. }\end{array}$ & $\begin{array}{l}\text { Discordo } \\
\text { Totalmente }\end{array}$ & Discordo & $\begin{array}{l}\text { Não concordo e } \\
\text { nem discordo }\end{array}$ & Concordo & $\begin{array}{l}\text { Concordo } \\
\text { totalmente }\end{array}$ \\
\hline 6. Acho importante as crianças arrumarem os brinquedos. & $\begin{array}{l}\text { Discordo } \\
\text { Totalmente }\end{array}$ & Discordo & $\begin{array}{l}\text { Não concordo e } \\
\text { nem discordo }\end{array}$ & Concordo & $\begin{array}{l}\text { Concordo } \\
\text { totalmente }\end{array}$ \\
\hline $\begin{array}{l}\text { 7. Meus amigos e vizinhos me procuram para que eu os } \\
\text { aconselhe. }\end{array}$ & $\begin{array}{l}\text { Discordo } \\
\text { Totalmente }\end{array}$ & Discordo & $\begin{array}{l}\text { Não concordo e } \\
\text { nem discordo }\end{array}$ & Concordo & $\begin{array}{l}\text { Concordo } \\
\text { totalmente }\end{array}$ \\
\hline $\begin{array}{l}\text { 8. No próximo ano terei mais dinheiro para gastar do que } \\
\text { tenho agora. }\end{array}$ & $\begin{array}{l}\text { Discordo } \\
\text { Totalmente }\end{array}$ & Discordo & $\begin{array}{l}\text { Não concordo e } \\
\text { nem discordo }\end{array}$ & Concordo & $\begin{array}{l}\text { Concordo } \\
\text { totalmente }\end{array}$ \\
\hline 9. Eu verifico preços mesmo para itens pequenos. & $\begin{array}{l}\text { Discordo } \\
\text { Totalmente }\end{array}$ & Discordo & $\begin{array}{l}\text { Não concordo e } \\
\text { nem discordo }\end{array}$ & Concordo & $\begin{array}{l}\text { Concordo } \\
\text { totalmente }\end{array}$ \\
\hline $\begin{array}{l}\text { 10. Escolho roupas da moda mesmo sendo } \\
\text { desconfortáveis. }\end{array}$ & $\begin{array}{l}\text { Discordo } \\
\text { Totalmente }\end{array}$ & Discordo & $\begin{array}{l}\text { Não concordo e } \\
\text { nem discordo }\end{array}$ & Concordo & $\begin{array}{l}\text { Concordo } \\
\text { totalmente }\end{array}$ \\
\hline 11. Gosto de festas onde há música e conversa. & $\begin{array}{l}\text { Discordo } \\
\text { Totalmente }\end{array}$ & Discordo & $\begin{array}{l}\text { Não concordo e } \\
\text { nem discordo }\end{array}$ & Concordo & $\begin{array}{l}\text { Concordo } \\
\text { totalmente }\end{array}$ \\
\hline 12. Faço trabalho voluntário. & $\begin{array}{l}\text { Discordo } \\
\text { Totalmente }\end{array}$ & Discordo & $\begin{array}{l}\text { Não concordo e } \\
\text { nem discordo }\end{array}$ & Concordo & $\begin{array}{l}\text { Concordo } \\
\text { totalmente }\end{array}$ \\
\hline 13. Ser mãe é a coisa mais importante da minha vida. & $\begin{array}{l}\text { Discordo } \\
\text { Totalmente }\end{array}$ & Discordo & $\begin{array}{l}\text { Não concordo e } \\
\text { nem discordo }\end{array}$ & Concordo & $\begin{array}{l}\text { Concordo } \\
\text { totalmente }\end{array}$ \\
\hline 14. Minha casa é limpa e arrumada. & $\begin{array}{l}\text { Discordo } \\
\text { Totalmente }\end{array}$ & Discordo & $\begin{array}{l}\text { Não concordo e } \\
\text { nem discordo }\end{array}$ & Concordo & $\begin{array}{l}\text { Concordo } \\
\text { totalmente }\end{array}$ \\
\hline 15. Me informo antes de comprar. & $\begin{array}{l}\text { Discordo } \\
\text { Totalmente }\end{array}$ & Discordo & $\begin{array}{l}\text { Não concordo e } \\
\text { nem discordo }\end{array}$ & Concordo & $\begin{array}{l}\text { Concordo } \\
\text { totalmente }\end{array}$ \\
\hline $\begin{array}{l}\text { 16. Daqui a cinco anos, o salário da família será maior do } \\
\text { que agora. }\end{array}$ & $\begin{array}{l}\text { Discordo } \\
\text { Totalmente }\end{array}$ & Discordo & $\begin{array}{l}\text { Não concordo e } \\
\text { nem discordo }\end{array}$ & Concordo & $\begin{array}{l}\text { Concordo } \\
\text { totalmente }\end{array}$ \\
\hline 17. Encontro bons preços nas propagandas de TV. & $\begin{array}{l}\text { Discordo } \\
\text { Totalmente }\end{array}$ & Discordo & $\begin{array}{l}\text { Não concordo e } \\
\text { nem discordo }\end{array}$ & Concordo & $\begin{array}{l}\text { Concordo } \\
\text { totalmente }\end{array}$ \\
\hline
\end{tabular}




\begin{tabular}{|c|c|c|c|c|c|}
\hline 18. Vestir roupas da moda é importante. & $\begin{array}{l}\text { Discordo } \\
\text { Totalmente }\end{array}$ & Discordo & $\begin{array}{l}\text { Não concordo e } \\
\text { nem discordo }\end{array}$ & Concordo & $\begin{array}{l}\text { Concordo } \\
\text { totalmente }\end{array}$ \\
\hline 19. Sou uma pessoa caseira. & $\begin{array}{l}\text { Discordo } \\
\text { Totalmente }\end{array}$ & Discordo & $\begin{array}{l}\text { Não concordo e } \\
\text { nem discordo }\end{array}$ & Concordo & $\begin{array}{l}\text { Concordo } \\
\text { totalmente }\end{array}$ \\
\hline 20. É gostoso trabalhar para a comunidade. & $\begin{array}{l}\text { Discordo } \\
\text { Totalmente }\end{array}$ & Discordo & $\begin{array}{l}\text { Não concordo e } \\
\text { nem discordo }\end{array}$ & Concordo & $\begin{array}{l}\text { Concordo } \\
\text { totalmente }\end{array}$ \\
\hline 21. Arrumo a minha casa para o conforto da família. & $\begin{array}{l}\text { Discordo } \\
\text { Totalmente }\end{array}$ & Discordo & $\begin{array}{l}\text { Não concordo e } \\
\text { nem discordo }\end{array}$ & Concordo & $\begin{array}{l}\text { Concordo } \\
\text { totalmente }\end{array}$ \\
\hline 22. Gosto quando minha casa está limpa. & $\begin{array}{l}\text { Discordo } \\
\text { Totalmente }\end{array}$ & Discordo & $\begin{array}{l}\text { Não concordo e } \\
\text { nem discordo }\end{array}$ & Concordo & $\begin{array}{l}\text { Concordo } \\
\text { totalmente }\end{array}$ \\
\hline 23. As tarefas domésticas são desagradáveis. & $\begin{array}{l}\text { Discordo } \\
\text { Totalmente }\end{array}$ & Discordo & $\begin{array}{l}\text { Não concordo e } \\
\text { nem discordo }\end{array}$ & Concordo & $\begin{array}{l}\text { Concordo } \\
\text { totalmente }\end{array}$ \\
\hline $\begin{array}{l}\text { 24. Uma pessoa economiza um bom dinheiro procurando } \\
\text { bons preços. }\end{array}$ & $\begin{array}{l}\text { Discordo } \\
\text { Totalmente }\end{array}$ & Discordo & $\begin{array}{l}\text { Não concordo e } \\
\text { nem discordo }\end{array}$ & Concordo & $\begin{array}{l}\text { Concordo } \\
\text { totalmente }\end{array}$ \\
\hline 25. Experimento os cortes de cabelo da moda. & $\begin{array}{l}\text { Discordo } \\
\text { Totalmente }\end{array}$ & Discordo & $\begin{array}{l}\text { Não concordo e } \\
\text { nem discordo }\end{array}$ & Concordo & $\begin{array}{l}\text { Concordo } \\
\text { totalmente }\end{array}$ \\
\hline 26. É bom trabalhar em campanha política. & $\begin{array}{l}\text { Discordo } \\
\text { Totalmente }\end{array}$ & Discordo & $\begin{array}{l}\text { Não concordo e } \\
\text { nem discordo }\end{array}$ & Concordo & $\begin{array}{l}\text { Concordo } \\
\text { totalmente }\end{array}$ \\
\hline 27. Ensino bons hábitos aos meus filhos. & $\begin{array}{l}\text { Discordo } \\
\text { Totalmente }\end{array}$ & Discordo & $\begin{array}{l}\text { Não concordo e } \\
\text { nem discordo }\end{array}$ & Concordo & $\begin{array}{l}\text { Concordo } \\
\text { totalmente }\end{array}$ \\
\hline 28. Na minha casa tem horário para tudo. & $\begin{array}{l}\text { Discordo } \\
\text { Totalmente }\end{array}$ & Discordo & $\begin{array}{l}\text { Não concordo e } \\
\text { nem discordo }\end{array}$ & Concordo & $\begin{array}{l}\text { Concordo } \\
\text { totalmente }\end{array}$ \\
\hline 29. Costuro as roupas de minha família. & $\begin{array}{l}\text { Discordo } \\
\text { Totalmente }\end{array}$ & Discordo & $\begin{array}{l}\text { Não concordo e } \\
\text { nem discordo }\end{array}$ & Concordo & $\begin{array}{l}\text { Concordo } \\
\text { totalmente }\end{array}$ \\
\hline
\end{tabular}




\section{Questionário de valores}

Informe o grau de importância que você atribui aos seguintes aspectos em sua vida pessoal.

\section{Conceitos e valores instrumentais}

\begin{tabular}{|c|c|c|c|c|c|}
\hline 1a. Ter dinheiro. & Nada importante & Pouco importante & Importante & Muito importante & Totalmente importante \\
\hline 2a. Relacionamento com os amigos. & Nada importante & Pouco importante & Importante & Muito importante & Totalmente importante \\
\hline 3a. Trabalho/emprego. & Nada importante & Pouco importante & Importante & Muito importante & Totalmente importante \\
\hline 4a. Ter estudo. & Nada importante & Pouco importante & Importante & Muito importante & Totalmente importante \\
\hline 5a. Divertimento. & Nada importante & Pouco importante & Importante & Muito importante & Totalmente importante \\
\hline 6a. Conforto material. & Nada importante & Pouco importante & Importante & Muito importante & Totalmente importante \\
\hline 7a. Guardar dinheiro. & Nada importante & Pouco importante & Importante & Muito importante & Totalmente importante \\
\hline 8a. Relacionamento familiar. & Nada importante & Pouco importante & Importante & Muito importante & Totalmente importante \\
\hline 9a. Ter saúde. & Nada importante & Pouco importante & Importante & Muito importante & Totalmente importante \\
\hline 10a. Realização dos sonhos. & Nada importante & Pouco importante & Importante & Muito importante & Totalmente importante \\
\hline 11a. Relacionamento com o companheiro. & Nada importante & Pouco importante & Importante & Muito importante & Totalmente importante \\
\hline 12a. Relacionamento com os filhos. & Nada importante & Pouco importante & Importante & Muito importante & Totalmente importante \\
\hline 13a. Ser reconhecido na comunidade. & Nada importante & Pouco importante & Importante & Muito importante & Totalmente importante \\
\hline 14a. Ser reconhecido no trabalho. & Nada importante & Pouco importante & Importante & Muito importante & Totalmente importante \\
\hline 15a. Viver de acordo com as regras religiosas. & Nada importante & Pouco importante & Importante & Muito importante & Totalmente importante \\
\hline
\end{tabular}

\section{Objetivos finais}

\begin{tabular}{|c|c|c|c|c|c|}
\hline 1b. Uma boa condição de vida. & Nada importante & Pouco importante & Importante & Muito importante & Totalmente importante \\
\hline 2b. Relacionamentos amorosos bons e duradouros. & Nada importante & Pouco importante & Importante & Muito importante & Totalmente importante \\
\hline 3b. Uma vida de sonhos realizados. & Nada importante & Pouco importante & Importante & Muito importante & Totalmente importante \\
\hline 4b. Ter o respeito das pessoas. & Nada importante & Pouco importante & Importante & Muito importante & Totalmente importante \\
\hline 5b. Aproveitar a vida. & Nada importante & Pouco importante & Importante & Muito importante & Totalmente importante \\
\hline 6b. Segurança para viver. & Nada importante & Pouco importante & Importante & Muito importante & Totalmente importante \\
\hline
\end{tabular}




\begin{tabular}{llllll}
\hline 7b. Ter respeito a mim mesmo. & Nada importante & Pouco importante & Importante & Muito importante & Totalmente importante \\
\hline 8b. Sentimento de ter alcançado o que desejei. & Nada importante & Pouco importante & Importante & Muito importante & Totalmente importante \\
\hline 9b. Chegar a Deus. & Nada importante & Pouco importante & Importante & Muito importante & Totalmente importante \\
\hline
\end{tabular}




\section{Anexo E - Termo de Consentimento Livre e Esclarecido}

Dados de Identificação do Sujeito da Pesquisa ou Responsável Legal

1. Nome:

Documento de identidade $\mathrm{N}^{\circ}$ : Sexo: ( ) M ( ) F

Data nascimento

Endereço:

$\mathrm{N}^{\circ}$

APT:

Bairro:

Cidade: CEP:

Telefone:

2. Responsável legal:

Grau de parentesco, tutor, curador, etc.:

Documento de identidade $\mathrm{N}^{\circ}$ : Sexo: () M ( ) F

Data nascimento

Endereço:

$\mathrm{N}^{\circ}$

APT: Bairro:

Cidade: CEP:

Telefone:

Dados sobre a pesquisa

1. Título do protocolo de pesquisa: Estilo de vida da família e seu impacto sobre a saúde da criança.

Pesquisador : Érica Bezerra Nobre (mestranda)

Orientador: Alexandre Archanjo Ferraro.

Cargo/função: professor doutor

Unidade do HCFMUSP: Departamento de pediatria.

2 Avaliação do risco da pesquisa:

$\begin{array}{lll}\text { RISCO MÍNIMO } & \text { RISCO MÉDIO } \\ \text { RISCO BAIXO } & \square & \text { RISCO MAIOR }\end{array}$

3. Duração da pesquisa: 24 meses 


\section{HOSPITAL DAS CLÍNICAS DA FACULDADE DE MEDICINA DA UNIVERSIDADE DE SÃO PAULO-HCFMUSP}

Nós estamos fazendo um levantamento para estudar a influência que o estilo de vida da família pode ter sobre a saúde da criança. Para isso serão aplicados questionários a você a fim de obter informações sobre grau de instrução, estado civil, classe econômica, estilo de vida da família e peso e estatura da criança, o consumo alimentar e nível de atividade física. Para responder ao questionário, precisará dispor de 60 minutos do seu tempo. Para coletar as informações de peso, é preciso que a criança esteja vestida somente com roupas leves. A pesagem será feita sem a presença de pessoas estranhas. Nós não divulgaremos a sua identificação e a da criança.

Esta pesquisa não Ihe dará benefícios ou vantagens, retorno financeiro ou algum tipo de custo e a qualquer momento a senhora poderá desistir de participar. Também terá direito de se manter informada sobre os resultados da pesquisa. Todos os dados serão utilizados somente para esta pesquisa.

Em qualquer etapa do estudo você terá acesso ao profissional responsável pela pesquisa para esclarecimento de dúvidas. O principal investigador é Érica Bezerra Nobre, que pode ser encontrada no endereço Av. Dr. Enéas Carvalho de Aguiar, № 647. Se tiver alguma dúvida, entre em contato com o telefone 30698672.

Eu discuti com a mestranda Érica Bezerra Nobre sobre a minha decisão em participar nesse estudo. Ficaram claros para mim quais são os propósitos do estudo, os procedimentos a serem realizados, seus desconfortos e riscos, as garantias de confidencialidade e de esclarecimentos permanentes. Ficou claro também que 
minha participação é isenta de despesas. Concordo voluntariamente em participar deste estudo e poderei retirar o meu consentimento a qualquer momento, antes ou durante o mesmo, sem penalidades ou prejuízo ou perda de qualquer benefício que eu possa ter adquirido.

Assinatura do paciente/representante legal

Data

Declaro que obtive de forma apropriada e voluntária o Consentimento Livre e Esclarecido deste paciente ou representante legal para a participação neste estudo.

(Somente para o responsável do projeto)

Data 


\section{REFERÊNCIAS}

1. Wilson DMC, Ciliska D. Lifestyle assessment: development and use of the FANTASTIC checklist. Can Fam Physician. 1984;30:1527-32.

2. Decina PA, McGregor M, Hagino C. Lifestyle analysis: a comparative study between freshman, second and fourth year chiropractic students. J Can Chiropr Assoc. 1990;34:69-74.

3. World Health Organization. Health promotion glossary. Geneva: World Health Organization; 1998.

4. Plachta-Danielzik S, Landsberg B, Johannsen M, Lange D, Müller MJ. Determinants of the prevalence and incidence of overweight in children and adolescents. Public Health Nutr. 2010;13:1870-81. [Abstract, PUBMED 2010].

5. BRASIL. Constituição, 1988. Constituição da República Federativa do Brasil. Brasília (DF): Senado; 1988.

6. World Health Organization. The Bangkok charter for health promotion in a globalized world. Bangkok: World Health Organization; 2005.

7. Rodriguez-Añez CR, Reis RS, Petroski EL. Versão brasileira do questionário "estilo de vida fantástico": tradução e validação para adultos jovens. Arquivos Brasileiros de Cardiologia. 2008;91:102-9. 
8. BRASIL. Câmara dos Deputados. Estatuto da Criança e do Adolescente. Lei n.8.069 de 13 de julho de 1990, Lei n.8.242 de 12 de outubro de 2001. 3a ed. Brasília: Coordenação de publicações; 2001. Disponível em: <http://redesocialsaopaulo.org.br/downloads/ECA.pdf>.

9. Costa COM, Bigras M. Mecanismos pessoais e coletivos de proteção e promoção da qualidade de vida para a infância e adolescência. Ciência e Saúde. 2007;12:1101-09.

10. Xi B, Mi J, Duan JL, Yan SJ, Cheng H, Dou DQ, Zhao XY. Familial clustering of obesity and the role of lifestyle factors among children in Beijing. Zhonghua Yu Fang Yi Xue Za Zhi. 2009;43:122-27. [Abstract, PUBMED2009].

11. Birch LL, Fisher JO. Mothers' child-feeding practices influence daughters' eating and weight. Am J Clin Nutr. 2000;71:1054-61.

12. Hirschler V, Buzzano K, Erviti A, Ismael N, Silva S, Dalamon R. Overweight and lifestyle behaviors of low socioeconomic elementary school children in Buenos Aires. BMC Pediatrics. 2009;9:17.

13. Greenberg RS, Ariza AJ, Binns HJ. Activity and dietary habits of mother and children: close ties. Clin Pediatr (Phila). 2010;49:1026-32. [Abstract, PUBMED 2010]. 
14. Schwandt P, Haas GM, Liepold E. Lifestyle and cardiovascular risk factors in 2001 child-parent pairs: the PEP Family Heart Study. Atherosclerosis. 2010;213:642-48. [Abstract, PUBMED 2010].

15. Petroski EL, Pelegrini A. Associação entre o estilo de vida dos pais e a composição corporal dos filhos adolescentes. Revista Paulista de Pediatria. 2009;27:48-52.

16. Villagran-Perez S, Rodriguez-Martin A, Novalbos-Ruiz, Martinez-Nieto JM, Lechuga-Campoy JL. Habits and lifestyles modifiable in children with overweight and obesity. Nutr Hosp. 2010;25:823-31. [Abstract, PUBMED 2010].

17. West F, Morawska A, Joughin K. The lifestyle behavior checklist: evaluation of the factor structure. Child Care Health Dev. 2010;36:508-15. [Abstract, PUBMED 2010].

18. Catenacci VA, Hill JO, Wyatt HR. The obesity epidemic. Clin Chest Med. 2009;30:415-44. [Abstract, PUBMED 2009].

19. Colombo RCR, Aguillar OM. Estilo de vida e fatores de risco em pacientes com primeiro episódio de infarto agudo do miocárdio. Revista LatinoAmericana de Enfermagem. 1997; 5:69-82. 
20. Webb E, Ashton CH, Kelly P, Kamali F. An update on Britisch medical students' lifestyles. Med Educ. 1998;32:325-31.

21. Kriaucioniene V, Petkevicien J, Klumbiene J. Dietary patterns and their association with lifestyle factors in Lithuanian adult population. Medicina (Kaunas). 2009;45:537-43.

22. Kumar S, Kumari A, Murarka S. Lifestyle factors and deteriorating male reproductive health. Indian J Exp Biol. 2009;47:615-24.

23. Burgalassi A, Ramacciotti CE, Bianchi M, Coli E, Polese L, Bondi E, Massimetti G, Dell'osso L. Caffeine consumption among eating disorder patients: epidemiology, motivations and potential of abuse. Eat Weight Disord. 2009;14:e212-18.

24. Batisky DL. Obesity and the role of lifestyle and dietary intervention in the management of pediatric hypertension. J Med Liban. 2010;58:171-74.

25. Greene GW, Schembre SM, White AA, Hoerr SL, Lohse B, Shoff S, Horacek T, Riebe D, Patterson J, Phillips BW, Kattelmann KK, Blissmer B. Identifying clusters of college students at elevated risk based on eating and exercise behaviors and psychosocial determinants of body weight. J Am Diet Assoc. 2001;111:394-400. 
26. Calamaro CJ, Mason TB, Ratchiffe SJ. Adolescents living the 24/7 lifestyle: effects of caffeine and technology on sleep duration and daytime functioning. Pediatrics. 2009;123:e1005-10.

27. Seo WS, Sung HM, Lee JH, Koo BH, Kim MJ, Kim SY, Choi SJ, Shin IH. Sleep patterns and their age-related changes in elementary-school children. Sleep Med. 2010;11:569-75.

28. Karevold E, Rovsamb E, Ystrom E, Mathiesen KS. Predictors and pathways from infancy to symptoms of anxiety and depression in early adolescence. Dev Psychol. 2009;45:1051-60.

29. Takakura M, Ueji M, Sakihara S. Covariation of cigarette smoking and other health-risk behaviors among Japanese high schook students: a preliminary study. J Epidemiol. 2001;11:224-28.

30. Psaltopouolou T, llias I, Alevizaki M. The role of diet and lifestyle in primary, secondary and tertiary diabetes prevention: a review of meta-analyses. Rev Diabet Stud. 2010;7:26-35.

31. He K, Kramer E, Houser RF, Chomitz VR, Hacker KA. Defining and understanding healthy lifestyles choices for adolescents. J Adolesc Health. 2004;35:26-33. 
32. Finotti MA. Contribuições ao estudo dos estilos de vida: comportamento de compra e uso de crédito [tese]. São Paulo: Faculdade de Economia, Administração e Contabilidade, Universidade de São Paulo; 2009.

33. Orth UR, Shellhammer MMT, Lopetcharat K. Promoting brand benefits: the role of consumer psychographics and lifestyle. J Consum Market. 2004;21:97108.

34. Wei R. Emergin lifestyles in China and consequences for perception of advertising, buying behavior and consumption preferences. Int $J$ Advert. 1997;16:261-75.

35. Wells WD, Tigert DJ. Activities, Interests and Opinions. J Advert Res. 1971;11:27-35.

36. Cosmas D. Life styles and consumption patterns. J Consum Res. 1982;8:45355.

37. Vyncke P. Lifestyle segmentation: from attitudes, interests and opinions, to values, aesthetic styles, life visions and media preferences. Eur J Commun. 2002;17:445-61.

38. Moreira JCT, Pasquale PP, Dubner AG. Dicionário de termos de marketing: definições, conceitos e palavras-chaves de marketing, propaganda, pesquisa, 
comercialização, comunicação e outras áreas correlatas a estas atividades. 4a ed. São Paulo: Atlas; 2003.

39. Fournier S, Antes D, Beaumier G. Nine consumption lifestyles. Adv Consum Res. 1992;19:329-37.

40. Bennett PD. Dictionary of Marketing Terms. American Marketing Association: 1988.

41. Holt DB. Poststructuralist lifestyle analysis: conceptualizing the social patterning of consumption in postmodernity. J Consum Res. 1997;23:326-50.

42. Engel JF, Blackwell RD, Miniard PW. Comportamento do consumidor. Rio de Janeiro: LTC - Livros Técnicos e Científicos; 2000.

43. Sheth JN. Comportamento do cliente: indo além do comportamento do consumidor. São Paulo: Atlas; 2001.

44. Lewis BR, Littler D. Dicionário enciclopédico de marketing. São Paulo: Atlas; 2001.

45. Kamakura WA, Wedel M. Life-style segmentation with tailored interviewing. $J$ Mark Res. 1995;32:308-17. 
46. Kucukemiroglu $\mathrm{O}$. Market segmentation by using consumer lifestyle dimensions and ethnocentrism: an empirical study. Eur J Mark. 1999;33:47087.

47. Kesic T, Piri-Rajh S. Market segmentation on the basis of food-related lifestyles of Croatina families. Br Food J. 2003;105:162-74.

48. Kassarjian HH. Personality and consumer behavior: a review. J Mark Res. 1971;7:409-18.

49. Kotler P. Administração de marketing: análise, planejamento, implementação e controle. São Paulo: Atlas; 1998.

50. Kahle LR, Beatty SE, Homer P. Alternative measurement approaches to consumer values: the list of values (LOV) and values and life styles (VALS). $J$ Consum Res. 1986;13:405-9.

51. Divine RL, Lepisto L. Analysis of the healthy lifestyles consumer. J Consum Market. 2005;22:275-83.

52. Prieto L, Badia X. Cuestionarios de salud: concepto y metodoloia. Aten Primaria. 2001;28:201-9. 
53. Reichenheim ME, Moraes CL. Desenvolvimento de instrumentos de aferição epidemiológicos. In: Kac G, Schieri R, Gigante D, organizadores. Epidemiologia Nutricional. Rio de Janeiro: Fiocruz; 2007. p. 227-43.

54. Pasquali L. Validade dos testes psicológicos: será possível reencontrar o caminho? Psicologia: teoria e pesquisa. 2007;23:99-107.

55. Bracher ESB. Adaptação e validação da versão em português da escala graduada de dor crônica para o contexto cultural brasileiro [tese]. São Paulo: Faculdade de Medicina, Universidade de São Paulo; 2008.

56. Pasquali L. Princípios de elaboração de escalas psicológicas. Revista de Psiquiatria Clínica. 1998;25:206-13.

57.Pasquali L. Psicometria. Revista da Escola de Enfermagem da USP. 2009;43:992-99.

58. Fleck MPA, Leal OF, Louzada S, Xavier M, Chachamovich E, Vieira G, Santos L, Pinzon V. Desenvolvimento da versão em português do instrumento de avaliação de qualidade de vida da OMS (WHOQOL-100). Revista Brasileira de Psiquiatria. 1999;21:19-28.

59. Guillemin F, Bombardier C, Beaton D. Cross-cultural adaptation of healthrelated quality of life measures: literature review and proposed guidelines. $J$ Clin Epidemiol. 1993;46:1417-1432. 
60. Streiner DL, Norman GR, organizadores. Health measurements scales: a practical guide to their development and use. New York: Oxford University Press; 2008.

61. Wardle J, Sanderson S, Guthrie CA, Rapoport L, Plomin R. Parental feeding style and the inter-generational transmission of obesity risk. Obes Res. 2002;10:453-62.

62. Gutierrez BAO. Tradução para o português e descrição do processo de validação do "Seattle Obstructive Lung Disease Questionnaire" [dissertação]. São Paulo: Escola de Enfermagem, Universidade de São Paulo; 2000.

63. Ferreira AFB. Tradução para a língua portuguesa e validação do questionário da saúde dos pés FHSQ (Foot Health Status Questionnaire) [tese]. São Paulo: Faculdade de Medicina, Universidade de São Paulo; 2005.

64. Conti MA, Latorre MRDO, Hearst N, Segurado A. Cross-cultural adaptation, validation and reliability of the body area scale for brazilian adolescents. Caderno de Saúde Pública. 2009;25:2179-86.

65. McDowell I. Measuring health: a guide to rating scales and questionnaires. New York: Oxford University Press; 2006. 
66. Sato FP. Validação da versão em português de um questionário para avaliação de autismo infantil [dissertação]. São Paulo: Faculdade de Medicina, Universidade de São Paulo; 2008.

67. Carvalho VO, Guimarães GV, Carrara D, Bacal F, Bocchi EA. Validação da versão em português do Minnesota Living with Heart Failure Questionnaire. Arquivos Brasileiros de Cardiologia. 2009;93(1):39-44.

68. Guyatt GH, Feeny DH, Patrick DL. Measuring health-related quality of life. Ann Intern Med. 1993;118:622-29.

69. Santos AS dos. Validação da escala de avaliação da qualidade de vida na doença cerebrovascular isquêmica para a língua portuguesa [tese]. São Paulo: Faculdade de Medicina, Universidade de São Paulo; 2007.

70. Cronbach LJ, Meehl PE. Construct validity in psychological tests. Psychol Bull. 1955;52:281-302.

71. Associação Brasileira de Estudos Populacionais. Critério de classificação econômica Brasil. ABEP; 2007.

72. Cardoso MA. Desenvolvimento, validação e aplicações de Questionários de Frequência Alimentar em estudos epidemiológicos. In: Kac G, Sichieri R, Gigante DP, organizadores. Epidemiologia nutricional. Rio de Janeiro: Fiocruz/Atheneu; 2007. p. 207. 
73. Norman, GR, Streiner DL. Exploratory Factor Analysis in PDQ Statistics, 3rd ed. London: BC Decker Inc; 2003. 